\title{
Common Pathophysiology in Multiple Mouse Models of Pitt-Hopkins Syndrome
}

\author{
(1)Courtney Thaxton, ${ }^{1,2 \star}$ Alexander D. Kloth, ${ }^{1,2 \star}$ Ellen P. Clark, ${ }^{1,2}$ Sheryl S. Moy, ${ }^{3,4}$ Raymond A. Chitwood, ${ }^{5}$ \\ and $\odot$ Benjamin D. Philpot ${ }^{1,2,4}$ \\ ${ }^{1}$ Department of Cell Biology and Physiology, ${ }^{2}$ Neuroscience Center, ${ }^{3}$ Department of Psychiatry, ${ }^{4}$ Carolina Institute for Developmental Disabilities, the \\ University of North Carolina, Chapel Hill, North Carolina 27599, and ${ }^{5}$ Center for Learning and Memory, Department of Neuroscience, University of Texas, \\ Austin, Texas 78712
}

\begin{abstract}
Mutations or deletions of the transcription factor TCF4 are linked to Pitt-Hopkins syndrome (PTHS) and schizophrenia, suggesting that the precise pathogenic mutations dictate cellular, synaptic, and behavioral consequences. Here, we generated two novel mouse models of PTHS, one that mimics the most common pathogenic TCF4 point mutation (human R580W, mouse R579W) and one that deletes three pathogenic arginines, and explored phenotypes of these lines alongside models of pan-cellular or CNS-specific heterozygous $T c f 4$ disruption. We used mice of both sexes to show that impaired $T c f 4$ function results in consistent microcephaly, hyperactivity, reduced anxiety, and deficient spatial learning. All four PTHS mouse models demonstrated exaggerated hippocampal long-term potentiation (LTP), consistent with deficits in hippocampus-mediated behaviors. We further examined R579W mutant mice and mice with pancellular Tcf4 heterozygosity and found that they exhibited hippocampal NMDA receptor hyperfunction, which likely drives the enhanced LTP. Together, our data pinpoint convergent neurobiological features in PTHS mouse models and provide a foundation for preclinical studies and a rationale for testing whether NMDAR antagonists might be used to treat PTHS.
\end{abstract}

Key words: autism; mouse; NMDA; Pitt-Hopkins syndrome; schizophrenia; TCF4

\section{Significance Statement}

Pitt-Hopkins syndrome (PTHS) is a rare neurodevelopmental disorder associated with TCF4 mutations/deletions. Despite this genetic insight, there is a need to identify the function of TCF4 in the brain. Toward this goal, we developed two mouse lines, including one harboring the most prevalent pathogenic point mutation, and compared them with two existing models that conditionally delete $T c f 4$. Our data identify a set of overlapping phenotypes that may serve as outcome measures for preclinical studies of PTHS treatments. We also discovered penetrant enhanced synaptic plasticity across mouse models that may be linked to increased NMDA receptor function. These data reveal convergent neurobiological characteristics of PTHS mouse models and support the further investigation of NMDA receptor antagonists as a possible PTHS treatment.

\section{Introduction}

Pitt-Hopkins syndrome (PTHS) is a rare neurodevelopmental disorder caused by mutation or deletion of the transcription fac-

Received May 10, 2017; revised Nov. 8, 2017; accepted Nov. 30, 2017.

Author contributions: C.T., A.D.K., S.S.M., R.A.C., and B.D.P. designed research; C.T., A.D.K., E.P.C., S.S.M., and R.A.C. performed research; C.T., A.D.K., S.S.M., and R.A.C. analyzed data; C.T., A.D.K., and B.D.P. wrote the paper.

This work was supported by the Pitt-Hopkins Research Foundation (B.D.P., C.T., and A.D.K.), University of Pennsylvania Orphan Disease Center Million Dollar Bike Ride (Grant MDBR-15-108-PH to B.D.P. and C.T.), the Brain and Behavior Research Foundation (NARSAD Young Investigator Grant 20653 to C.T.), and the National Institute of General Medical Sciences (Training, Workforce Development and Diversity Grant K12GM000678 to A.D.K.). Confocal imaging was supported by the National Institute of Neurological Disorders and Stroke (Grant P30NS045892) and the Eunice Kennedy Shriver National Institute of Child Health and Human Development (NICHD Grant U54HD79124). The mouse behavioral phenotyping core was supported by the NICHD (Grant U54HD079124 to S.S.M.). We thank Natallia Riddick and Viktoriya Nikolova for work on behavioral phenotyping, Dan Holmberg (Lund University, Sweden) for Tcff ${ }^{\text {Flox }}$ mice, and Tonis Timmusk (Tallinn University, Estonia) for luciferase constructs.

The authors declare no competing financial interests. tor 4 gene TCF4 located in chromosomal region 18q21.1 (Amiel et al., 2007; Zweier et al., 2007, 2008). PTHS is associated with intellectual disability, seizures, loss of speech, microcephaly, reductions in hippocampal volume, and other neuroanatomical abnormalities (Amiel et al., 2007; Brockschmidt et al., 2007; Zweier et al., 2008; Rosenfeld et al., 2009; de Pontual et al., 2009; Whalen et al., 2012; Marangi and Zollino, 2015). Although de novo mutations or deletions in one copy of TCF4 cause PTHS, alterations in TCF4 have also been linked to autism and schizophrenia (Stefansson et al., 2009; Blake et al., 2010; Hasi et al.,

\section{${ }^{*}$ C.T. and A.D.K. contributed equally to this work.}

Correspondence should be addressed to Dr. Benjamin D. Philpot, University of North Carolina School of Medicine, 115 Mason Farm Road, Chapel Hill, NC 27599-7545. E-mail: bphilpot@med.unc.edu.

D0I:10.1523/JNEUROSCI.1305-17.2017

Copyright $\odot 2018$ the authors $\quad 0270-6474 / 18 / 380918-19 \$ 15.00 / 0$ 
2011; Navarrete et al., 2013; Quednow et al., 2014; Stessman et al., 2017), suggesting a need to identify the role of TCF4 in the pathophysiology of these disorders.

TCF4 (also known as E2-2, ITF2, and SEF-2) encodes a basic helix-loop-helix (bHLH) transcription factor that regulates gene transcription through homodimerization or heterodimerization with other bHLH transcription factors, including several neuronspecific bHLH transcription factors. TCF4 is highly expressed during embryonic and early postnatal development (de Pontual et al., 2009) and has particularly high expression in the hippocampus (Brzózka et al., 2010; Sepp et al., 2011; Navarrete et al., 2013). Mice with reduced (Kennedy et al., 2016) or increased (Brzózka et al., 2010) Tcf4 expression exhibit severe cognitive deficits. Together, these findings suggest that perturbation of TCF4 may disrupt synaptic function in the hippocampus and other regions, resulting in impaired learning and memory.

Approximately 30\% of PTHS individuals have loss-of-function mutations or deletions of TCF4; the remaining 70\% of individuals with PTHS have missense mutations, nonsense mutations, or small insertion-deletions (indels) that can result in dominant-negative isoforms of TCF4 protein (Whalen et al., 2012). Such mutant TCF4 isoforms can perturb the function of wild-type TCF4 as well as other bHLH transcription factors (Sepp et al., 2011, 2012; Tamberg et al., 2015), making it difficult to predict their functional impact. Therefore, it is critical to identify the common and distinct pathophysiological disruptions that arise across multiple genetic subtypes of PTHS because this will ultimately facilitate therapeutic strategies for PTHS. Toward this goal, we developed two novel mouse models, one that harbors the highly prevalent R580W (mouse R579W) point mutation and one that has a small in-frame deletion that eliminates three pathogenic arginines, and studied them in parallel with existing PTHS mouse models. We found that these PTHS model mice exhibited remarkably consistent behavioral and electrophysiological deficits, which can serve as a basis for preclinical studies. Our data indicate that hippocampal NMDA receptor (NMDAR) hyperfunction is a highly penetrant feature of PTHS and thus presents an important translational opportunity.

\section{Materials and Methods}

Animals

All mice were raised on a 12:12 light:dark cycle with ad libitum access to food and water. The $T c f 4^{\mathrm{Flox} /+}$ mice were previously generated in the laboratory of Dan Holmberg (Bergqvist et al., 2000) and were maintained on a C57BL/ 6 background. The $\beta$-Actin-Cre (JAX stock \# 019099, RRID:IMSR_JAX:019099) and Nestin-Cre (JAX stock \#003771, RRID:IMSR_JAX:003771) mice were purchased from The Jackson Laboratory and maintained on a C57BL/6 background. Homozygous $\beta$-Actin-Cre mice were bred with heterozygous $T c f 4{ }^{\mathrm{Flox} /+}$ mice to produce the Tcf4 $4^{\mathrm{Flox} /+}::$ Actin-Cre line (cHet). Heterozygous Nestin-Cre mice were bred with homozygous $T c f 4^{\text {Flox/Flox }}$ mice to produce the Tcf $4^{\text {Flox/+ }}::$ Nestin-Cre line (CNS-Het). Littermate controls consisted of the genotypes $T c f 4^{+/+}$and $T c f 4^{\text {Flox/+ }}$. All Tcf4 mutant mice used were heterozygous for the Tcf4 mutation because homozygous mutations of Tcf4 result in embryonic to postnatal day 1 (P1) lethality. Experiments were conducted in strict compliance with protocols approved by the Institutional Animal Care and Use Committee at the University of North Carolina-Chapel Hill (UNC).

Generation and confirmation of mouse models

The Tcf4 ${ }^{\mathrm{R} 579 \mathrm{~W}}(\mathrm{R} 579 \mathrm{~W})$ and $T c f 4^{\triangle 574-579}(\triangle 574-579)$ mouse models were generated using CRISPR/Cas9 technology by the Animals Models Core facility at UNC. The sequence of the guide RNA (gRNA) was $5^{\prime}$ AATGCCCGTGAGCGCCTGAGGG-3' (the bold sequence is the PAM) and was targeted to bp 2253-2274 of mouseTcf4. The sequence of DNA containing the R579W codon change (R579W-T RNA) was 5' -AAGGCT GAGCGCGAGAAGGAACGGAGGATGGCCAATAATGCCCGTGAG CGCCTGTGGGTCCGAGATATCAACGAGGCTTTCAAGGAGCTTG GCCGTATGGTGCAGCTC-3'. A silent mutation oligo (5'-AAGGCT GAGCGCGAGAAGGAACGGAGGATGGCCAATAATGCCCGTGAG CGGCTCAGAGTCCGAGATATCAACGAGGCTTTCAAGGAGCTTG GCCGTATGGTGCAGCTC-3') was also used to encourage insertion of the oligos on both alleles with no deleterious effects. C57BL/6J embryos were microinjected with a mixture of $10 \mathrm{ng} / \mu \mathrm{l}$ Cas 9 mRNA (in vitro transcribed and polyadenlyated RNA), $10 \mathrm{ng} / \mu \mathrm{l}$ Tcf4 guide RNA (purified and in vitro transcribed RNA), and $100 \mathrm{ng} / \mu \mathrm{l} \mathrm{TCF} 4 \mathrm{R} 579 \mathrm{~W}$-T oligo. Embryonic injections produced a unique founder with an indel containing an insertion of the silent mutation oligo and an $18 \mathrm{bp}$ in-frame deletion of aa $574-579$ of $T c f 4$ was generated $(\triangle 574-579)$, as well as two founder mice heterozygous for the R579W mutation. Founders from each mutation were checked for off-target effects of the guide RNA. No changes to any other nontargeted gene(s) of interest were found. The R579W and $\triangle 574-579$ mice were maintained on a C57BL/6 background. These mice were genotyped by Sanger sequencing using the following steps: (1) DNA from either a small toe, tail, or ear sample was extracted; (2) the PCR product of $\sim 500 \mathrm{bp}$ was amplified using a forward primer mTCF4 Intron 17-FP (5' -CCAGCTCATCCCTTCCATTTG-3') and a reverse primer mTCF4 Intron 18-RP ( $5^{\prime}$-CAATCATGTCTGAGG ATTGAG-3'); (3) the PCR product was purified using the ISOLATE II PCR and Gel Kit (Bioline) according to the manufacturer's instructions; and (4) the purified product was sequenced by Sanger sequencing (Eton Biosciences) using the nested primer Nest mTCF4 R579W Seq-FP (5'CAATAACGATGATGAGGACC-3'). Either the A-to-T transition at bp 1135 for R579W mice or the presence of deletion beginning at bp 1119 for the $\triangle 574-579$ was used to confirm heterozygosity of the mutant alleles.

\section{Luciferase assays}

Constructs. We used the following constructs described previously (Sepp et al., 2011, 2012): mouse TCF4 (pcDNA3.1_mTCF4-B ${ }^{-}$), human AchaeteScute homolog 1 [ASCL1; pCDNA3.1_hASCL1(m)], $12 \mu$ E5 promoter containing the luciferase reporter Photinus pyralis (pGL4.29 [luc2P_12mE5_Hygro]), and a control minimal reporter that expresses Renilla reniformis (pGL4[hRlucP_min_Hygro]).

Mutagenesis. To generate mouse Tcf4 ${ }^{\mathrm{R} 575 \mathrm{Q}}$ (R575Q), Tcf4 ${ }^{\mathrm{R} 577 \mathrm{H}}$ (R577H), Tcf4 ${ }^{\mathrm{R} 579 \mathrm{~W}}(\mathrm{R} 579 \mathrm{~W}), T c f 4^{\mathrm{R} 581 \mathrm{P}}(\mathrm{R} 581 \mathrm{P})$, and Tcf4 ${ }^{\Delta 574-579}$ $(\triangle 574-579)$ mutations, we mutagenized the pCDNA3.1_mTCF4-B ${ }^{-}$ (Tcf4) construct using the Velocity Mutagenesis kit (Bioline) according to the manufacturer's instructions. We used the following primers for mutagenesis: for R575Q, the forward primer is GGCCAATAATGCCCA GGAGCGCCTGAGGGTCC and the reverse primer is GGACCCTCA GGCGCTCCTGGGCATTATTGGCC; for R577H the forward primer is CCAATAATGCCCGTGAGCACCTGAGGGTCCGAG and the reverse primer is CTCGGACCCTCAGGTGCTCACGGGCATTATTGG; for R579W the forward primer is GCCCGTGAGCGCCTGTGGGTCCGA GATATC and the reverse primer is GATATCTCGGACCCACAGGCG CTCACGGGC; for R581P the forward primer is GCGCCTGAGGGTCCC AGATATCAACGAGGC and the reverse primer is GCCTCGTTGATA TCTGGGACCCTCAGGCGC; for $\triangle 574-579$ the forward primer is GGA GGATGGCCAATAAT-GTCCGAGATATCAACGAGGC and the reverse primer is GCCTCGTTGATATCTCGGAC-ATTATTGGCCATCCTCC. We used the following cycling parameters: $98^{\circ} \mathrm{C}$ for $2 \mathrm{~min}$; 18 cycles of $98^{\circ} \mathrm{C}(30 \mathrm{~s}), 57^{\circ} \mathrm{C}(30 \mathrm{~s}), 68^{\circ} \mathrm{C}(5.5 \mathrm{~min})$; and $68^{\circ} \mathrm{C}(5 \mathrm{~min})$. The $\mathrm{mu}-$ tagenized PCR products were digested with Dpn 1 for $30 \mathrm{~min}$ at $37^{\circ} \mathrm{C}$. Beta-mercaptoethanol $(2 \mu \mathrm{l})$ was added to the DpnI-digested products and transformed into BioBlue (Bioline) chemically competent cells by heat shock for $30 \mathrm{~s}$ at $42^{\circ} \mathrm{C}$, followed by incubation on ice for $2 \mathrm{~min}$. Prewarmed SOC/LB medium (500 $\mu \mathrm{l})$ was added and the transformed cells were incubated at $37^{\circ} \mathrm{C}$ with shaking $(170 \mathrm{rpm}$ ) for at least $1 \mathrm{~h}$ before plating on LB agar plates supplemented with ampicillin $(100 \mu \mathrm{g} / \mathrm{ml})$ and incubated overnight at $37^{\circ} \mathrm{C}$. Clones were picked from the plates and grown in LB medium $(5 \mathrm{ml})$ supplemented with ampicillin $(100 \mu \mathrm{g} / \mathrm{ml})$ overnight at $37^{\circ} \mathrm{C}$. An aliquot of the bacterial prep was mixed with $50 \%$ glycerol and stored at $-80^{\circ} \mathrm{C}$. The remaining prep was extracted for the 
plasmid DNA using the ISOLATE II Plasmid mini kit (Bioline) according to the manufacturer's instructions. The plasmid DNA was sequenced by Sanger sequencing using the mTCF4 Intron 17-FP primer (described above) to identify positive clones.

Cell culture. HEK293T cells were grown in D10 medium supplemented with $10 \%$ fetal bovine serum (FBS) and penicillin-streptomycin (PenStrep; $10 \mathrm{U} / \mathrm{ml}$; Thermo Fisher Scientific) at $37^{\circ} \mathrm{C}$ in $50 \% \mathrm{CO}_{2}$. Cells were maintained in the $10 \% \mathrm{FBS} / \mathrm{Pen}$-Strep/D10 medium and passaged every 2-3 d. For the luciferase assays, the HEK293T cells were passaged and plated into 48 -well plates and maintained in 10\% FBS/Pen-Strep/D10 medium before transfection.

Transfections. HEK293T cells were transfected with cDNA constructs for luciferase assays using the LipoD293 transfection reagents as described previously (Sepp et al., 2011, 2012). For each luciferase assay, the $12 \mu \mathrm{E} 5$ promoter construct and the minimal reporter $R$. reniformis construct were cotransfected with either empty vector (pCDNA3.1 alone), mTCF4 (Tcf4), R575Q, R577H, R579W, R581P, or $\Delta 574-579$ constructs. A total of 150 ng of cDNA was transfected per well, with equal amounts of cDNA from the $12 \mu \mathrm{E} 5$ promoter construct and the minimal reporter $R$. reniformis constructs. The HEK293T cells were incubated with transfection medium containing all of the cDNAs for $12-18 \mathrm{~h}$ at $37^{\circ} \mathrm{C}$ in $50 \%$ $\mathrm{CO}_{2}$. After transfection, the medium was replaced with fresh D10/FBS/ Pen-Strep medium. The cells were used for luciferase assays $24-48 \mathrm{~h}$ after transfection.

Luciferase assays. The Dual-Glo Luciferase Assay System (Promega) was used according to the manufacturer's instructions. The transfected cells were extracted in $50 \mu \mathrm{l}$ of passive lysis buffer using the above kit and assayed on a luminometer. As a background control, untransfected cell lysate was used to assess any inherent luminescence in the lysates. The background level was subtracted from all values obtained from transfections containing the $12 \mu \mathrm{E} 5$ promoter construct and these values were further normalized to the minimal reporter $R$. reniformis signal.

\section{Behavioral testing}

All behavioral testing was performed through the UNC Mouse Phenotyping Core. Testing began when animals were between 6 and 8 weeks of age and ended when they were between 16 and 21 weeks of age.

Elevated plus maze. The elevated plus maze is constructed to have two open arms and two closed arms, all $20 \mathrm{~cm}$ in length; the height in the closed arms is $30 \mathrm{~cm}$. The entire maze is elevated $50 \mathrm{~cm}$ above the floor. Mice were given $15 \mathrm{~min}$ trial on the elevated plus maze. For testing, the mice were placed on the center section $(8 \times 8 \mathrm{~cm})$ and allowed to explore the maze freely. Time and the number of entries into the open and closed arms were recorded. For the R579W mice, only data from the male mice from the first cohort are presented due to the high variability in the results from the females (two controls, three R579W). The second cohort of R579W did not undergo testing on the elevated plus maze.

Open field test. The mice were given a $60 \mathrm{~min}$ trial in an open-field chamber $(41 \times 41 \times 30 \mathrm{~cm})$ that was crossed by a grid of photobeams (VersaMax system; AccuScan Instruments). Counts were taken of the number of photobeams broken during the $60 \mathrm{~min}$ trial in $5 \mathrm{~min}$ intervals. Measures included locomotor activity (total distance traveled) and time spent in the center region.

Rotarod. The mice were tested for motor coordination and learning on an accelerating rotarod (Ugo Basile SRL). For initial testing, the mice were given three trials with $45 \mathrm{~s}$ between each trial. Two additional trials were given $48 \mathrm{~h}$ later. The initial rotation speed was set at $3 \mathrm{rpm}$ and progressed to a maximum of $30 \mathrm{rpm}$ across a 5 min maximum trial duration. The latency to fall from the top of the rotating barrel was recorded.

Three-chamber social approach task. The social testing apparatus was a rectangular, three-chambered box fabricated from clear Plexiglas. The dividing walls had doorways allowing access into each chamber. An automated image tracking system (Ethovision, RRID:SCR_000441; Noldus) provided measures of time spent in each chamber and the number of entries into each chamber. Each subject was allowed an initial habituation period when they could explore the fully open chamber freely for 10 min. After habituation, the test mouse was enclosed in the center compartment of the social test box. The first novel mouse (Novel 1) was placed in one of the side chambers and was enclosed in a small Plexiglas cage drilled with holes, allowing for nose contact. An identical empty Plexiglas cage was placed in the opposite side of the chamber. After placement of the Novel 1 mouse and the empty cage, the doors were reopened and the subject was allowed to explore the social test box for 10 min. At the end of the sociability phase, another novel mouse (Novel 2) was placed in the empty Plexiglas container. The test mouse was again enclosed within the center region and then allowed to explore the social test box and chambers containing the Novel 1 mouse or the Novel 2 mouse for $10 \mathrm{~min}$. Each novel mouse used was sex and strain matched to the test mouse. For the R579W cohort, only the male data are presented due to the low number and high variability in the female cohort.

Acoustic startle. Mice were tested twice: the first test was between 7 and 12 weeks of age and the second test at 16-21 weeks of age. For each test, mice were placed into individual small Plexiglas cylinders within larger, sound-attenuating chambers (San Diego Instruments SR-Lab system). Each cylinder was seated upon a piezoelectric transducer that quantified the vibrations. The chambers include a ceiling light, a fan, and a loudspeaker for the acoustic stimuli. Background sound levels (70 dB) and calibration of the acoustic stimuli were confirmed with a digital sound level meter (San Diego Instruments). Each session began with a 5 min habituation period, followed by 42 trials (seven of each type): nostimulus trials, acoustic startle stimulus alone ( $120 \mathrm{~dB}$ for $40 \mathrm{~ms}$ ) trials, and prepulse stimulus ( $20 \mathrm{~ms} ; 74,78,82,86$, or $90 \mathrm{~dB}$ ) trials that occurred $100 \mathrm{~ms}$ before the onset of the acoustic startle stimulus. Measures were taken of the startle amplitude for each trial across a $65 \mathrm{~ms}$ sampling window. An overall analysis was performed for each subject's data for levels of prepulse inhibition at each prepulse sound level, calculated as $100-[$ (response amplitude for prepulse stimulus and startle stimulus together/response amplitude for startle stimulus alone) $\times 100]$. For the R579W cohort, combined data from both cohorts are presented for the first test (7-11 weeks) for both acoustic startle and pre-pulse inhibition. For the second test of acoustic startle, only the first cohort of R579W mice is presented.

Morris water maze. The water maze consisted of a large circular pool (diameter, $122 \mathrm{~cm}$ ) partially filled with water $\left(45 \mathrm{~cm}\right.$ deep, $24-26^{\circ} \mathrm{C}$ ) located in a room with numerous visual cues. The procedure involved three different phases: (1) a visible platform test, (2) acquisition in the hidden platform task, and (3) a test for reversal learning. For the visible platform test, each mouse was given 4 trials/d for $2 \mathrm{~d}$ to swim to an escape platform cued by a patterned cylinder extending above the surface of the water. For each trial, the mouse was placed in the pool at one of four possible locations (randomly ordered) and then given $60 \mathrm{~s}$ to find the visible platform. If the mouse found the platform, the trial ended and the animal was allowed to remain for $10 \mathrm{~s}$ on the platform before the next trial began. If the platform was not found, the mouse was placed on the platform for $10 \mathrm{~s}$ and then given the next trial. Measures were taken of latency to find the platform and swimming speed via an automated tracking system (Ethovision; Noldus). After the visible platform task, mice were tested for their ability to find a submerged, hidden escape platform (diameter, $12 \mathrm{~cm}$ ). Each animal was given 4 trials per day with 1 min per trial to swim to the hidden platform. The criterion for learning was an average group latency of $15 \mathrm{~s}$ or less to locate the platform. Mice were tested until the group reached criterion, with a maximum of $9 \mathrm{~d}$ of testing. After the acquisition phase, mice were tested for reversal learning using the same procedure described above. In this phase, the hidden platform was relocated to the opposite quadrant in the pool. Measures were taken of latency to find the platform. For the initial cohort of R579W mice, the acquisition and hidden tasks were only performed for $3 \mathrm{~d}$, whereas the second cohort was tested for $7 \mathrm{~d}$ for the hidden task (only the first $5 \mathrm{~d}$ are shown in Fig. 6). Similarly, the first R579W cohort was only tested for $3 \mathrm{~d}$ for the reversal versus $8 \mathrm{~d}$ for the second cohort.

\section{Histology and microscopy}

A set of adult mice was perfused for brain collection and histology was performed. Mice were deeply anesthetized with sodium pentobarbital $(60 \mathrm{mg} / \mathrm{kg}$, i.p.) before being transcardially perfused with room temperature paraformaldehyde in PBS. Brains were removed from the skull and placed in fixative overnight at $4^{\circ} \mathrm{C}$; the brains were then cryoprotected in 
$20 \%$ sucrose in PBS for $12 \mathrm{~h}$ and $30 \%$ sucrose in PBS thereafter. Coronal brain slices were collected using a freezing sliding microtome (Thermo Fisher Scientific) at a thickness of $30 \mu \mathrm{m}$ after the brains were frozen on dry ice. Sections were cryopreserved at $-20^{\circ} \mathrm{C}$ in a solution of $45 \%$ PBS, $30 \%$ ethylene glycol, and $25 \%$ glycerol by volume.

In preparation for imaging, tissue sections were washed at least two times in PBS for $20 \mathrm{~min}$, stored overnight, then washed at least three times in PBST for $30 \mathrm{~min}$ and again in PBS for $20 \mathrm{~min}$. The sections were then incubated for 60-120 min in NeuroTrace 640/660 Deep-Red Fluorescent Nissl Stain (1:100 in PBS; Thermo Fisher Scientific) and/or DAPI (1:3000 in PBS) and then washed in PBS and mounted on gelatinized slides. Comparative brain sections within figures were stained within the same experiment under identical conditions.

Mounted tissue sections from the forebrain were imaged using a Zeiss LSM 710 confocal microscope. Single-plane optical slices were acquired with a $10 \times$ objective $(10 \times / 0.3$ Neofluar $)$ with $1 \times$ averaging. Images were obtained by tiling micrographs of 512 pixels $\times 512$ pixels $(1.66 \mu \mathrm{m}$ pixel size, $848.5 \mu \mathrm{m} \times 848.5 \mu \mathrm{m}$ image size) that were stitched together using Zen imaging software (correlation threshold, 9.0). Images were then adjusted for angle, brightness, and contrast and then merged using ImageJ software (RRID:SCR_003070). Images compared within figures were acquired using identical acquisition parameters. All images to be compared underwent identical manipulations for brightness and contrast.

\section{Electrophysiology}

For electrophysiological recordings, P60-P120 sex-matched, age-matched mutant mice and control littermates were used. All reagents were purchased from Sigma-Aldrich unless otherwise specified. All drugs were prepared as stock aliquots in water and stored at $-20^{\circ} \mathrm{C}$.

Hippocampal slice preparation. Mice were anesthetized with an overdose of pentobarbital (Euthasol; Virbac) diluted in distilled water. The brain was quickly dissected and blocked. For extracellular field recordings, mice were decapitated rapidly after the cessation of the toe-pinch reflex and the brain was quickly dissected and blocked. Then, hippocampal sections were cut transversely at a thickness of $350 \mu \mathrm{m}$ in ice-cold oxygenated cutting solution containing the following (in $\mathrm{mm}$ ): $87 \mathrm{NaCl}$, $2.5 \mathrm{KCl}, 1.25$ sodium monobasic monophosphate, $25 \mathrm{NaHCO}_{3}, 10 \mathrm{dex}-$ trose, 75 sucrose, 1.3 sodium ascorbate, $0.5 \mathrm{CaCl}_{2}$, and $7 \mathrm{MgCl}_{2}$ bubbled with $95 \% \mathrm{O}_{2} / 5 \% \mathrm{CO}_{2}$ on a Leica $1000 \mathrm{~S}$ vibrating microtome. During slicing, hippocampal area CA3 was removed. Slices recovered for $>60$ min at $32^{\circ} \mathrm{C}$ in oxygenated artificial CSF (ACSF) containing the following (in $\mathrm{mm}$ ): $124 \mathrm{NaCl}, 3 \mathrm{KCl}, 1.25$ sodium monobasic monophosphate, 26 $\mathrm{NaHCO}_{3}, 20$ dextrose, $2 \mathrm{CaCl}_{2}$, and $1 \mathrm{MgCl}_{2}$ bubbled with $95 \% \mathrm{O}_{2} / 5 \%$ $\mathrm{CO}_{2}$ before recordings. For whole-cell recordings, mice were transcardially perfused after the cessation of the toe-pinch reflex with ice-cold cutting solution containing the following (in $\mathrm{mm}$ ): $2.5 \mathrm{KCl}, 1.25$ sodium monobasic monophosphate, $25 \mathrm{NaHCO}_{3}, 7$ dextrose, 1.3 sodium ascorbate, 3 sodium pyruvate, 210 sucrose, $7 \mathrm{MgCl}_{2}$, and $0.5 \mathrm{CaCl}_{2}$ and the brain was quickly dissected. Then, the hippocampus was blocked to expose the transverse surface (Bischofberger et al., 2006) and cut at a thickness of $300-350 \mu \mathrm{m}$ in ice-cold cutting solution. Slices recovered for $20 \mathrm{~min}$ at $35^{\circ} \mathrm{C}$ followed by $>40$ min at room temperature in ACSF (same as above, with the addition of $10 \mathrm{~mm}$ dextrose, $3 \mathrm{~mm}$ sodium pyruvate, and $1.3 \mathrm{~mm}$ sodium ascorbate added to the recovery chamber) before recordings.

Field potential recordings. Slices were placed in a submersion recording chamber (Warner Instruments) perfused with oxygenated ACSF at a rate of $1.5-1.75 \mathrm{ml} / \mathrm{min}$ and maintained at a temperature of $30-32^{\circ} \mathrm{C}$. Extracellular recording micropipettes were pulled (P-97; Sutter Instruments) from thin borosilicate glass (fire-polished with filament; outer diameter, $1.0 \mathrm{~mm}$; inner diameter, $0.78 \mathrm{~mm}$; length, $10 \mathrm{~cm}$; Sutter Instruments) and filled with ACSF. Field EPSPs (fEPSPs) were recorded from micropipettes placed in the stratum radiatum of hippocampal area CA1 in response to stimulation of Schaffer collaterals by a 2-contact platinum/ iridium cluster electrode $(2 \times 25 \mu \mathrm{m}$; FHC) placed $300-500 \mu \mathrm{m}$ from the recording electrode. Signals were filtered between $0.1 \mathrm{~Hz}$ and $3 \mathrm{kHz}$, amplified, and sampled at a rate of $10 \mathrm{kHz}$ using pCLAMP 9.2 software (RRID:SCR_011323; Molecular Devices). To set the stimulation intensity, an input/output (I/O) characteristic for the slice was first generated by monitoring the postsynaptic response (measured as the slope of the
fEPSP during $0.7 \mathrm{~ms}$ following the fiber volley) evoked by brief pulses $(200 \mu \mathrm{s} ; 2-60 \mathrm{~mA})$ delivered every $15 \mathrm{~s}$ and then selecting the current that elicited $40-60 \%$ of the maximum response within the stimulation range. For analysis of I/O characteristics, we omitted trials in which the presence of a population spike occluded our ability to measure fEPSP slope accurately. For analysis of fiber volley, we included only recordings in which the evoked fiber volley was discernible. In a subset of experiments, the paired-pulse ratio was tested before the induction of LTP using two iterations of a family of interpulse intervals $(20-100 \mathrm{~ms}, 20 \mathrm{~ms}$ steps, followed by $50-300 \mathrm{~ms}, 50 \mathrm{~ms}$ steps). Evoked responses were then monitored every $30 \mathrm{~s}(0.03 \mathrm{~Hz})$ for $\geq 20 \mathrm{~min}$ to record a stable baseline ( $<5 \%$ increase over the last $15 \mathrm{~min}$ of monitoring). After a stable baseline was achieved, slices were stimulated with 1 of 4 stimulation protocols: $31 \mathrm{~s} 100 \mathrm{~Hz}$ bursts separated by $20 \mathrm{~s} ; 31 \mathrm{~s} 40 \mathrm{~Hz}$ bursts separated by $20 \mathrm{~s}$; $31 \mathrm{~s} 20 \mathrm{~Hz}$ bursts separated by $20 \mathrm{~s}$; or 900 pulses at $1 \mathrm{~Hz}$ (15 min). Monitoring of synaptic responses resumed shortly after the cessation of stimulation and fEPSP slopes were recorded every $30 \mathrm{~s}$ for $45 \mathrm{~min}$. Experiments were aligned to the time of stimulation and changes in synaptic strength were measured by comparing the average fEPSP slopes to $30-45 \mathrm{~min}$ after conditioning with the baseline response $0-15 \mathrm{~min}$ before stimulation. Some experiments were performed in the presence of $100 \mu \mathrm{M} D, L$-2-amino-5-phosphonopentanoic acid ( $D, L$-APV; Tocris Bioscience).

Whole-cell recordings. Slices were placed in a submersion recording chamber (Harvard Apparatus), perfused with oxygenated ACSF at a rate of $2 \mathrm{ml} / \mathrm{min}$, and maintained at a temperature of $30-32^{\circ} \mathrm{C}$. Hippocampal area CA1 pyramidal cells were visualized using a Zeiss Examiner microscope outfitted with infrared differential interference contrast optics. Patch pipettes were pulled (P-97; Sutter Instruments) from thick-walled borosilicate glass (fire-polished with filament; outer diameter, $1.5 \mathrm{~mm}$; inner diameter, $0.86 \mathrm{~mm}$; length, $10 \mathrm{~cm}$; Sutter Instruments). Open-tip resistances were $2-5 \mathrm{M} \Omega$. For voltage-clamp experiments, the patch pipettes were backfilled with a cesium-based internal solution containing the following (in mM): $100 \mathrm{CsCHSO}_{3}, 15 \mathrm{CsCl}, 2.5 \mathrm{MgCl}_{2}, 10 \mathrm{HEPES}, 5$ QX-314, 5 BAPTA, $4 \mathrm{Mg}$-ATP, and $0.3 \mathrm{Mg}$-GTP, pH adjusted to 7.25 with $1 \mathrm{M} \mathrm{CsOH}$; osmolarity adjusted to $\sim 300 \mathrm{mOsm}$ with sucrose (Berrios et al., 2016). For current-clamp experiments, the patch pipettes were backfilled with a potassium-based internal solution containing the following (in $\mathrm{mM}$ ): 100 potassium gluconate, $20 \mathrm{KCl}, 10 \mathrm{HEPES}, 0.2$ EGTA, $4 \mathrm{Mg}$-ATP, $0.3 \mathrm{Na}-\mathrm{GTP}, 10 \mathrm{Na}_{2}$ phosphocreatine, $\mathrm{pH}$ adjusted to $7.2-3$ with $1 \mathrm{M} \mathrm{KOH}$; osmolarity adjusted to 290-300 mOsm with sucrose (Wallace et al., 2012). In some experiments, the internal solution contained $0.025 \mathrm{~mm}$ Alexa Fluor 594 hydrazide (Thermo Fisher Scientific). Recordings were performed in the whole-cell configuration using a patch-clamp amplifier (Multiclamp 700B; Molecular Devices) and a data acquisition driven by PClamp 10 software (Molecular Devices). To obtain recordings in voltage-clamp mode, initial pipette seal resistances exceeded $1 \mathrm{G} \Omega$, fast and slow pipette capacitive transients were compensated for before break-in, and cells were held at a holding potential of $-70 \mathrm{mV}$. For current-clamp recordings, the amplifier switched into current-clamp mode after 3-5 min wash-in of the internal, the resting membrane potential (RMP) was recorded at a holding current of $I_{\mathrm{inj}}=0$ $\mathrm{pA}$, the bridge was balanced, and the pipette capacitance was compensated. Changes in series and input resistances were monitored every $30 \mathrm{~s}$ throughout the experiments. Data were excluded if series resistances exceeded $30 \mathrm{M} \Omega$. For current-clamp experiments, the bridge was balanced before each recording protocol.

All voltage-clamp recordings were performed in the presence of $2 \mu \mathrm{M}$ gabazine (Abcam) to isolate EPSPs. For evoked-current experiments, a 2 -contact platinum/iridium cluster stimulating electrode $(2 \times 25 \mu \mathrm{m}$; FHC) was placed in the stratum radiatum $\sim 250 \mu \mathrm{m}$ orthogonal to the recording site ( $50 \%$ layer depth). Once whole-cell voltage-clamp recordings were established at a holding potential of $-70 \mathrm{mV}$, the intensity of the stimulus $(200 \mu \mathrm{s}, 0.05 \mathrm{~Hz})$ was adjusted to elicit AMPA receptor (AMPAR)-elicited EPSCs with an amplitude of 250-350 pA that remained stable for $2 \mathrm{~min}$. AMPAR majority currents were then recorded for 15 sweeps. Mixed NMDA receptor (NMDAR)-mediated EPSCs were recorded at a holding potential of $+40 \mathrm{mV}$ for 15 sweeps. NMDAR-toAMPAR analysis (NMDA/AMPA) for each cell were computed by mea- 
suring the average amplitude $50 \mathrm{~ms}$ after stimulus onset of mixed EPSCs collected at $+40 \mathrm{mV}$ (the NMDAR-specific component) and the average peak amplitude of EPSCs collected at $-70 \mathrm{mV}$ (the AMPAR-specific component) dividing the AMPAR-specific component by the NMDARspecific component (Etherton et al., 2011). In addition, the decay kinetics of NMDAR-mediated EPSCs were analyzed by computing the decay time constant.

NMDAR-mediated EPSCs were well fit in Clampfit (Molecular Devices) by a double exponential using the equation $I(t)=I_{\mathrm{f}} \exp \left(-t / \tau_{\mathrm{f}}\right)+$ $I_{\mathrm{s}} \exp \left(-t / \tau_{\mathrm{s}}\right)$, where $I$ is the current amplitude, $t$ is time, $I_{\mathrm{f}}$ and $I_{\mathrm{s}}$ are the peak amplitudes of the slow and fast components of the current, respectively, and $\tau_{\mathrm{f}}$ and $\tau_{\mathrm{s}}$ are the decay time constants, respectively; the overall weighted decay constant, $\tau_{\mathrm{w}}$, was quantified as $\tau_{\mathrm{w}}=\tau_{\mathrm{f}}{ }^{*}\left[I_{\mathrm{f}} /\left(I_{\mathrm{f}}+I_{\mathrm{s}}\right)\right]+\tau_{\mathrm{s}}{ }^{*}$ $\left[I_{\mathrm{s}} /\left(I_{\mathrm{f}}+I_{\mathrm{s}}\right)\right]$ (Philpot et al., 2001; de Marchena et al., 2008). NMDARmediated EPSCs were confirmed from recordings performed at a holding potential of $+40 \mathrm{mV}$ after ACSF supplemented with $20 \mu \mathrm{M}$ DNQX (Abcam) was washed onto the slice; effectiveness of DNQX wash-on was confirmed by the loss of AMPAR-mediated EPSCs at a holding potential of $-70 \mathrm{mV}$.

In some experiments, $5 \mu \mathrm{M}$ 4-[2-(4-benzylpiperidin-1-yl)-1-hydroxypropyl]phenol (ifenprodil (+)-tartrate; Abcam) $+20 \mu \mathrm{M}$ DNQX was washed onto the slice for $20 \mathrm{~min}$ while the cell was maintained at a holding potential of $-70 \mathrm{mV}$. After wash-on, the effect of ifenprodil on NMDAR-mediated EPSC amplitude and decay time constant $\tau_{\mathrm{w}}$ by ifenprodil was computed as the ratio of the postdrug to predrug values.

All current-clamp recordings were performed in the presence of $2 \mu \mathrm{M}$ gabazine (Abcam), $100 \mu \mathrm{M} \mathrm{D,L-APV} \mathrm{(Tocris} \mathrm{Bioscience),} \mathrm{and} 20 \mu \mathrm{M}$ DNQX (Abcam) to block inhibitory, NMDAR-mediated excitatory, and AMPAR-mediated excitatory currents, respectively. Passive membrane properties were measured from the response to a family of hyperpolarizing and depolarizing current steps (500 ms, $-150 \mathrm{pA}$ to $50 \mathrm{pA}$ in $20 \mathrm{pA}$ steps, $1 \mathrm{~s}$ intertrial interval) (Routh et al., 2009; Dembrow et al., 2010). Membrane time constant was determined from the responses to 100 alternating hyperpolarizing and depolarizing pulses $(2 \mathrm{~ms},-400 \mathrm{pA}$ and $+400 \mathrm{pA}$, delivered with the minimum possible intertrial interval) (Routh et al., 2009; Dembrow et al., 2010). The relationship between firing frequency and current magnitude was determined from a family of depolarizing current steps $(1000 \mathrm{~ms}, 50 \mathrm{pA}$ to $400 \mathrm{pA}, 15 \mathrm{~s}$ intertrial interval) (Routh et al., 2009; Dembrow et al., 2010).

Data from current-clamp experiments were analyzed in Clampfit (Molecular Devices). Input resistance was computed as the slope of the best-fit linear line of the voltage-current plot generated from the family of hyperpolarizing and depolarizing current steps. The sag ratio was computed as the proportional increase of the maximum negative-going voltage transient relative to the steady-state voltage transient in response to hyperpolarizing current steps. The rebound was computed as the slope of the best-fit linear line of the plot showing the relationship between the steady-state voltage transient and the maximum positive-going voltage transient at the cessation of the current step relative to the holding potential. The membrane time constant $\left(\tau_{\mathrm{m}}\right)$ was computed as the slow component of a double-exponential fit $\left(V_{\mathrm{m}}(t)=A_{\text {slow }} \exp \left(-t / \tau_{\text {slow }}\right)\right)+$ $A_{\text {fast }} \exp \left(-t / \tau_{\text {fast })}+C\right)$ of the average response to hyperpolarizing and depolarizing current steps. Single action potentials were analyzed to yield spiking threshold (where the upward voltage inflection first exceeds $\left.d V_{\mathrm{m}} / d t=20\right)$, maximum $d V_{\mathrm{m}} / d t$, spike amplitude, and spike halfmaximum width. Firing rate was determined using the Clampfit thresholdcrossing algorithm across the $1 \mathrm{~s}$ current injection.

\section{Experimental design and statistical analysis}

All experiments were conducted blinded to genotype. Minimum sample sizes were estimated from previously published datasets with similar experimental parameters. For behavior, electrophysiology, and brain and body weight experiments, measurements were drawn from mutant animals and their age-matched, sex-matched littermates and we attempted to balance the number of animals drawn from each sex. For behavior experiments, the sample sizes were as follows: $11 \mathrm{cHet}$ mutant mice (5 males, 6 females) and 10 controls ( 5 males, 5 females); a cohort of 12 R579W mutant mice (10 males, 2 females) and 12 controls ( 9 males, 3 females), and second cohort of 9 R579W mutant mice ( 5 males, 4 fe- males) and 9 controls ( 5 males, 4 female), where the R579W cohorts were combined for all tests (21 pairs total, sexes combined) except for the 3 -chamber assay test, in which only the male data from the first cohort were used. For extracellular field recording measurements, we used $\geq 6$ slices for each set with no more than 2 slices per animal. For whole-cell recordings, we used $\geq 7$ cells with at least 4 mice per genotype/experiment. Data were analyzed using GraphPad Prism 6 software (RRID: SCR_002798). Statistical outliers were identified by the Prism ROUT routine and removed from further analysis. For hypothesis testing, we used unpaired two-sample $t$ tests and one-way and two-way repeatedmeasures ANOVA, as described in the Results and figure legends. For behavioral data, "protected" Fisher's least significant difference (LSD) post hoc tests were conducted if a significant $F$ value was detected by two-way ANOVA. All other post hoc tests were unpaired two-sample $t$ tests corrected for multiple comparisons using the Bonferroni correction. Data are depicted as mean \pm SEM unless otherwise indicated.

\section{Results}

\section{Generation and validation of PTHS mouse models}

The bHLH region in exon 18 of TCF4 is a hotspot for missense mutations associated with PTHS (Whalen et al., 2012), including highly penetrant mutations at arginine residues R576Q, R578H, R580W, and R582P (mouse R575Q, R577H, R579W, and R581P, respectively). The most common PTHS mutation to date is the R580W missense mutation, which disrupts the ability of TCF4 to bind DNA (Zhuang et al., 1996; Whalen et al., 2012; Hsu et al., 2014; Rannals et al., 2016b). To target these common mutation sites, we used the CRISPR/Cas9 gene editing technology to produce a PTHS mouse model that specifically modeled the R580W (mouse R579W) point mutation. During this process, we also serendipitously generated a mouse with an in-frame deletion of six amino acids (aa 574-579) on one allele and the insertion of a silent mutation on the other allele $(\Delta 574-579$ mice) affecting three of five known pathogenic arginines and potentially having a more severe phenotypic presentation (Fig. $1 A, B$ ). Homozygosity in these mice was embryonically lethal, similar to mice with homozygous loss of Tcf4 (Zhuang et al., 1996; Rannals et al., 2016b).

To test the transcriptional activity of mutant TCF4, we performed luciferase assays by transfecting HEK293 cells with wild-type or mutant TCF4, a control plasmid carrying Renilla luciferase $(h R l u c P)$, and the firefly luciferase gene $(l u c 2 P)$ under the control of $12 \mu \mathrm{E} 5$ (CACCTG) E-boxes (Sepp et al., 2011, 2012). All four causative point mutations perturbed significantly the ability of TCF4 to activate the $12 \mu \mathrm{E} 5$ promoter (Fig. $1 C$; one-way ANOVA, $F_{(5,12)}=54.69, p<0.0001$; post hoc unpaired $t$ tests with Bonferroni corrections $-\mathrm{R} 575 \mathrm{Q}, t_{(12)}=12.82, p<$ $0.0001 ; \mathrm{R} 577 \mathrm{H}, t_{(12)}=12.82, p<0.0001 ; \mathrm{R} 579 \mathrm{~W}, t_{(12)}=12.78$, $\left.p<0.0001 ; \mathrm{R} 581 \mathrm{P}, t_{(12)}=12.82, p<0.0001\right)$. Comparatively, the $\Delta 574-579$ deletion was significantly less transcriptionally active than wild-type TCF4 (Fig. $1 D$; one-way ANOVA, $F_{(3,8)}=23.28, p=$ 0.0003; post hoc unpaired $t$ test with Bonferroni correction for $\left.\Delta 574-579, t_{(8)}=6.823, p=0.0007\right)$. These studies demonstrate that perturbation of the bHLH domain severely impairs TCF4 transcriptional activity and emphasizes the pathogenicity of these mutations in PTHS.

E-proteins such as TCF4 can promote transcription either independently or through homodimerization or heterodimerization to other E-proteins, including ASCL1 (Achaete-Scute homolog 1) (Sepp et al., 2012). To test whether the R579W and $\Delta 574-579$ mutant constructs altered ASCL1 enhanced transcription, we transfected HEK293 cells with TCF4, ASCL1, or ASCL1 combined with either wild-type TCF4, the R579W mutant, or the $\Delta 574-579$ mutant (Fig. $1 E$ ). Consistent with previous results (Sepp et al., 2012), we found that TCF4 and ASCL1 indepen- 
A

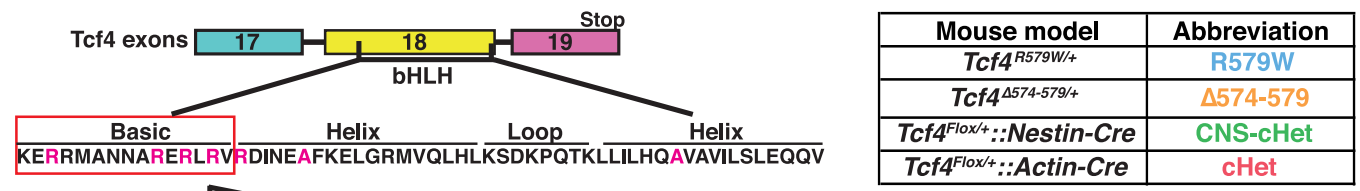

B

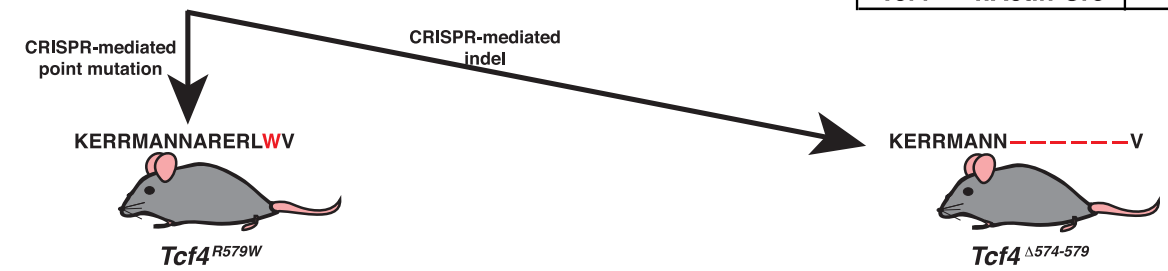

B11

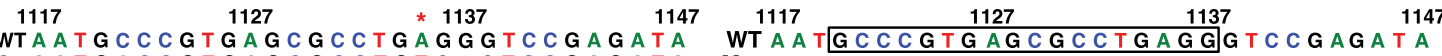

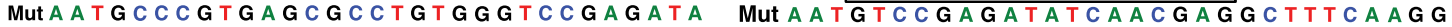
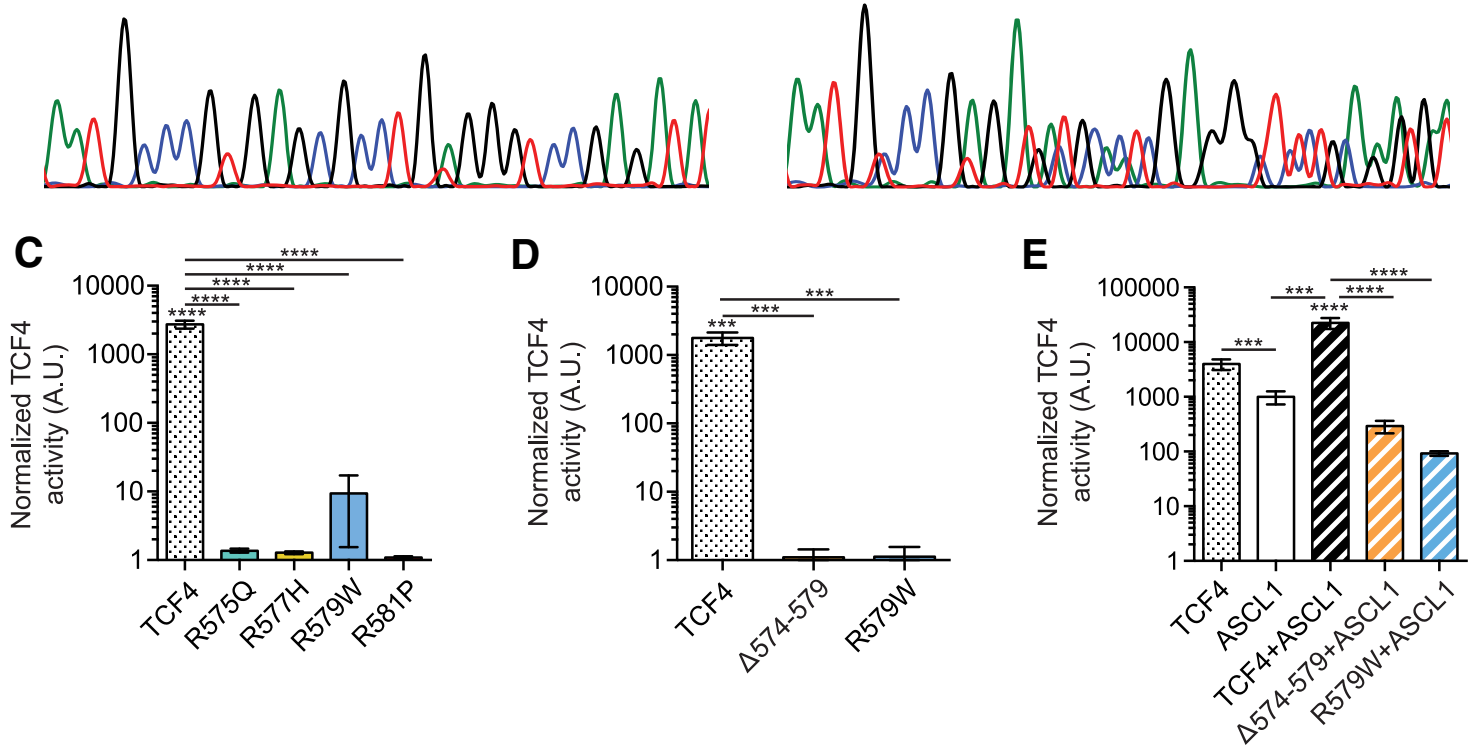

Figure 1. Generation and validation of PTHS model mice that express a dominant-negative form of TCF4. A, Several mutation sites (pink text) within the bHLH region (exon 18, yellow) are associated with PTHS. We generated mice with a pathogenic point mutation $\left(T C C_{4}{ }^{\mathrm{RS} 79 \mathrm{~W}} ; \mathrm{R579W}\right.$ ) or a unique in-frame deletion that removes three of five pathogenic arginines associated with PTHS $\left(T c f 4{ }^{\Delta 74-579} ; \triangle 574-579\right)$. The table lists mouse models and abbreviations used in this study. $\boldsymbol{B}$, Electropherograms showing heterozygosity of the mutations: a $c .1735 \mathrm{~A}>\mathrm{T}$ transition in the R579W mice and a c.1120_1137del frameshift mutation in the $\triangle 574-579$ mice. C, Transcriptional activity measured by luciferase assays of wild-type TCF4 and pathogenic point mutations. D. Transcriptional activity of wild-type TCF4 compared with the R579W and $\triangle 574-579$ variants. E, Transcriptional activity of TCF4, the transcriptional activator ASCL1, R579W, or $\triangle 574-579$ constructs (orange hash) either alone or in combination as indicated. Data represent mean \pm SEM. Post hoc unpaired $t$ tests with Bonferroni correction: ${ }^{* * *} p \leq 0.001,{ }^{* * * *} p \leq 0.0001$.

dently supported transcriptional activity and, when combined, their transcriptional activities were enhanced (one-way ANOVA, $F_{(5,12)}=3.043, p<0.0001$; post hoc unpaired $t$ tests: TCF4 vs TCF4+ASCL1, $t_{(12)}=6.314, p=0.0005$; ASCL1 vs TCF4+ASCL1, $t_{(12)}=7.33, p=0.0001$; control vs TCF4+ASCL1, $t_{(12)}=7.669, p<$ $0.0001)$. However, the R579W and $\Delta 574-579$ mutant constructs reduced transcriptional activity with ASCL1 significantly compared with wild-type TCF4 (post hoc unpaired $t$ tests with Bonferroni corrections; TCF4+ASCL4 vs R579W+ASCL1, $t_{(12)}=7.638, p<$ 0.0001 ; TCF4+ASCL4 vs $\Delta 574-579+$ ASCL1, $t_{(12)}=7.638, p<$ $0.0001)$. These findings further suggest that the R579W mutation produces a TCF4 variant that, at least partially, acts in a dominantnegative fashion (Sepp et al., 2011, 2012; Tamberg et al., 2015) and indicate that the unique $\Delta 574-579$ indel produces a similar dominant-negative consequence.

We next characterized these two new PTHS mouse models alongside an existing conditional deletion mouse model $\left(T c f 4^{\text {Flox/+ }}\right.$ ) that we used to produce either pan-cellular or CNS-specific Tcf4 deletion. Exons 18-20 are flanked by loxP sites in the Tcf $4^{\text {Flox/+ }}$ mice (Bergqvist et al., 2000) such that Cre recombinase (Cre)-mediated excision of the loxP sites heterozygously removes the bHLH region of Tcf4 similar to that observed in Tcf4 ${ }^{+\prime-}$ mice (Zhuang et al., 1996; Rannals et al., 2016a, b). We generated two conditional deletion mouse models: (1) a ubiquitous deletion by crossing Tcf $4^{\text {Flox/+ }}$ mice with $\beta$-Actin-Cre transgenic mice (cHet), which allowed us to mimic pan-cellular heterozygous disruption of Tcf4, and (2) a CNS-specific deletion by crossing Tcf $4^{\mathrm{Flox} /+}$ mice with Nestin-Cre mice (CNScHet), which allowed us to eliminate consequences of peripheral Tcf4 heterozygosity (Grubišić et al., 2015) that could affect growth trajectories.

As an initial measure of the consequences of Tcf 4 disruption, we measured body weight and brain weight of PTHS model mice and their sex- and age-matched littermate controls (Fig. 2). We observed significant effects or trends for smaller body and brain weights in all four PTHS mouse models: R579W and CNS-cHet mice had significantly reduced body and brain weights compared with controls (Fig. 2A,C; unpaired two-sample $t$ test; $n=17$ R579W and 19 control; body weight, $t_{(34)}=2.186, p=0.0358$; brain weight, $t_{(34)}=2.858, p=0.0072 ; n=9$ CNS-cHet and 10 control; body weight, $t_{(17)}=7.522, p<0.0001$; brain weight, $t_{(17)}=$ 
A

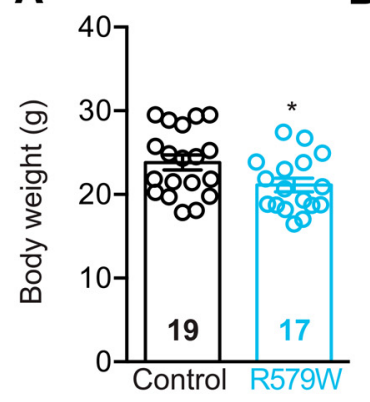

B

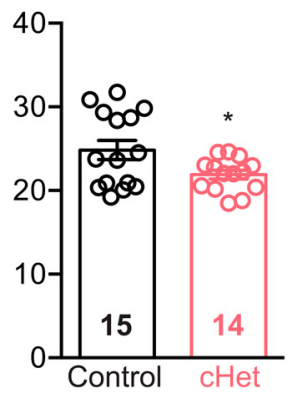

C

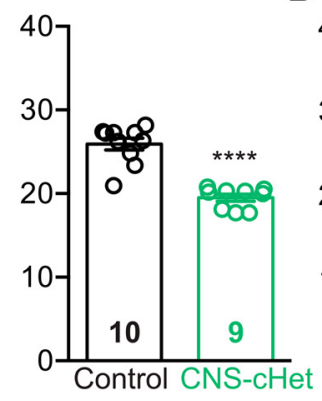

D

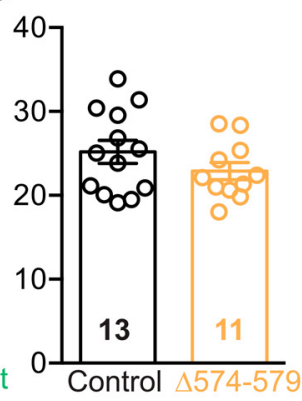

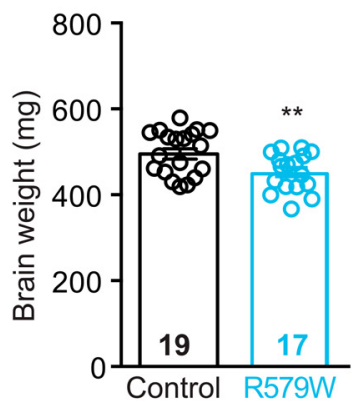
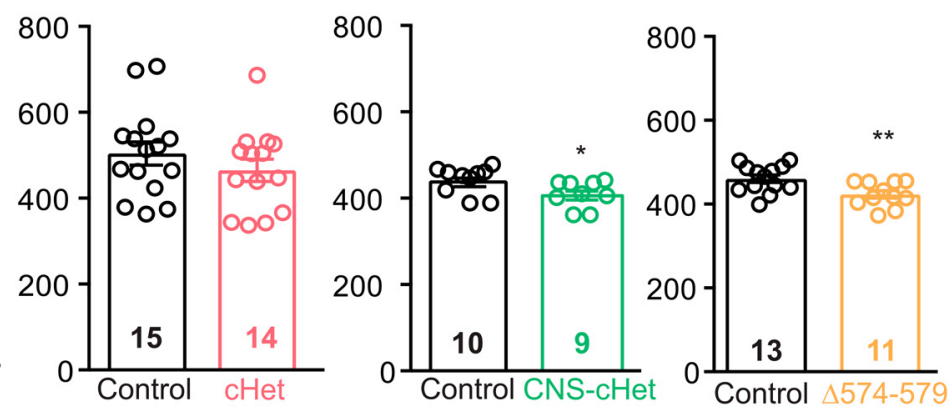

E

Control

R579W

Control
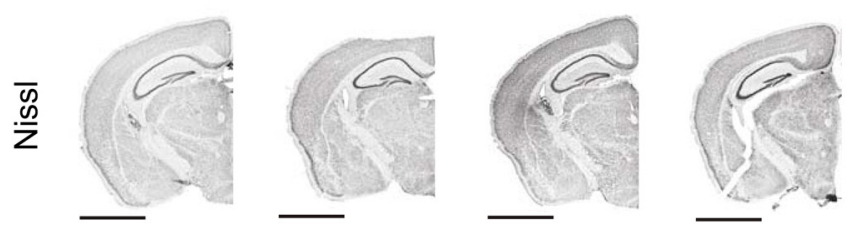

cHet

Control

$\triangle 574-579$
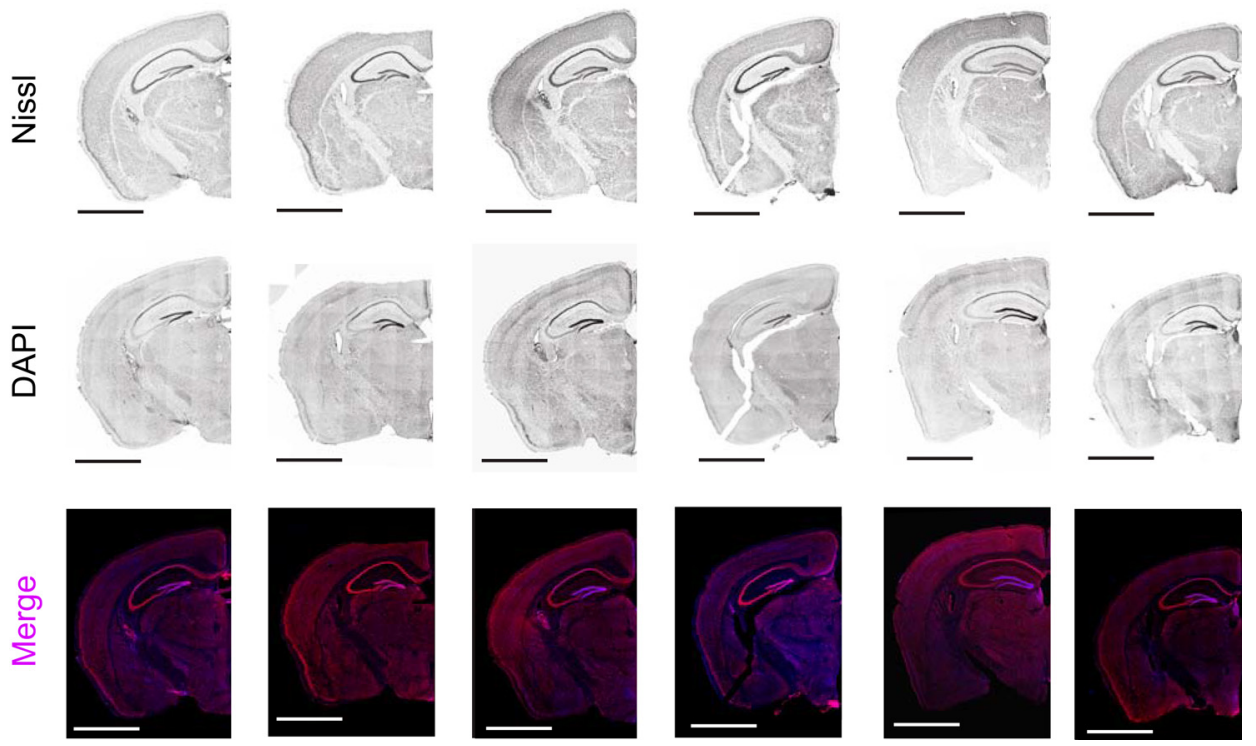

Figure 2. PTHS model mice have reduced body and brain weight. $\boldsymbol{A}-\boldsymbol{D}$, Body and brain weights of adult (P70-P90) control littermates compared with R579W mice (A), CHet mice (B), CNS-CHet mice $(\boldsymbol{C})$, and $\triangle 574-579$ mice $(\boldsymbol{D})$. Data represent individual data points and mean \pm SEM. ${ }^{*} p \leq 0.05,{ }^{* *} p \leq 0.01,{ }^{* * * *} p \leq 0.0001$. E, Representative NeuroTrace- (Nissl-), DAPI-, and merged stained coronal sections of adult control littermates compared with R579W mice, chet, and $\triangle 574-579$ mice. Scale bar, $2 \mathrm{~mm}$.

2.208, $p=0.0413)$. Similarly, $\Delta 574-579$ mice exhibited significant reductions in brain weight, whereas cHet mice exhibited significant reductions in body weight (Fig. $2 B, D$; unpaired twosample $t$ tests; $n=11 \Delta 574-579$ and 13 control; body weight, $t_{(22)}=$ 1.287, $p=0.2115$; brain weight, $t_{(22)}=2.914, p=0.008 ; n=14$ cHet and 15 control, $t_{(27)}=2.241, p=0.0335$; brain weight, $t_{(27)}=$ $1.042, p=0.3069)$. The reduction in brain weight appeared, at least qualitatively, to be a consequence of uniform reductions in brain volume, as demonstrated by Nissl- and DAPI-stained coronal series from R579W, cHet, and $\triangle 574-579$ mice compared with controls (Fig. 2E). The gross reduction in brain size in PTHS model mice suggests that they have a relative microcephaly.
Increased activity and reduced anxiety in PTHS model mice

To begin examining convergent and divergent behavioral phenotypes across mouse models, we tested R579W and cHet mouse models and their sex-matched littermate controls in a battery of behavioral tasks. In the open-field task, both the R579W and cHet PTHS model mice showed increased activity (Fig. 3A; two-way repeated-measures ANOVA; $n=21$ R579W and 21 control; genotype effect, $F_{(1,40)}=18.31, p=0.0001$; time effect, $F_{(11,440)}=$ 49.97, $p<0.0001$; genotype $\times$ time interaction, $F_{(11,440)}=$ $0.8241, p=0.6160 ; n=11 \mathrm{cHet}$ and 10 control; genotype effect, $F_{(1,40)}=8.445, p=0.0091 ;$ time effect, $F_{(11,440)}=11.68, p<$ 0.0001 ; genotype $\times$ time interaction, $F_{(11,440)}=0.694, p=$ 

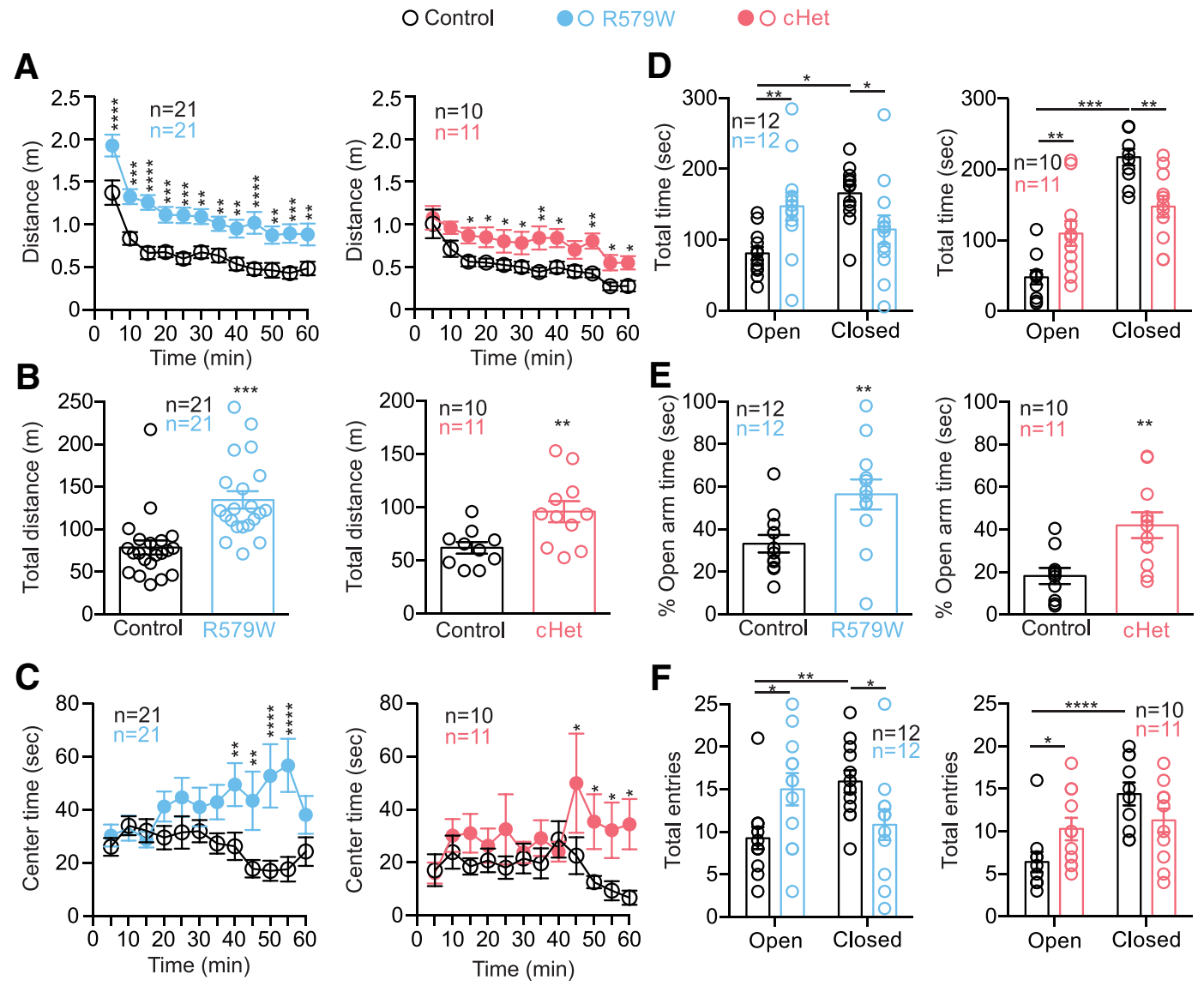

Figure 3. TCF4 mutant mice are hyperactive and show reduced anxiety. Behavioral data from the open-field $(\boldsymbol{A}-\boldsymbol{C})$ and elevated plus maze $(\boldsymbol{D}-\boldsymbol{F})$ tasks. $\boldsymbol{A}$, Distance traveled in an open field plotted in $5 \mathrm{~min}$ intervals. $\boldsymbol{B}$, Total distance traveled in the open field over a $1 \mathrm{~h}$ testing period. $\boldsymbol{C}$, Center time in an open field plotted in $5 \mathrm{~min}$ intervals. $\boldsymbol{D}$, Time spent in either the closed or open arms of an elevated plus maze. $\boldsymbol{E}$, Percentage of time spent in the open arms. $\boldsymbol{F}$, Total number of entries made into either the closed or open arms. Data represent mean \pm SEM and individual data points are plotted when feasible. Protected Fisher's LSD tests following significant ANOVA effects $(\boldsymbol{A}, \boldsymbol{C}, \boldsymbol{D}, \boldsymbol{F})$ or unpaired two-sample $t$ tests $(\boldsymbol{B}, \boldsymbol{E}):{ }^{*} p \leq 0.05,{ }^{* *} p \leq 0.01,{ }^{* * *} p \leq$ $0.001,{ }^{* * * *} p \leq 0.0001$.

$0.7436)$ and total distance traveled (Fig. 3B; unpaired two-sample $t$ tests; $n=21$ R579W and 21 control; $t_{(40)}=4.279, p<0.0001$; $n=10 \mathrm{cHet}$ and 11 control; $\left.t_{(19)}=1.899, p=0.0728\right)$, consistent with previous findings in Tcf $4^{+/-}$model mice (Kennedy et al., 2016; Rannals et al., 2016a, b). These results also highlight a possible deficit in habituation to novel environments in the cHet mice; both cHet mice and controls show a similar level of activity at the outset of the task, but the level of activity appears to wane more slowly for the cHet mice (Fig. 3A). We assessed time spent in the center region of the novel open field as a measure of anxiety and found that both the R579W and cHet mice spent significantly more time in the center region during the last $20 \mathrm{~min}$ of the trial (Fig. 3C; two-way repeated-measures ANOVA; $n=21 \mathrm{R} 579 \mathrm{~W}$ and 21 control; genotype effect, $F_{(1,40)}=0.0079, p=0.0079$; time effect, $F_{(11,440)}=0.8317, p=0.6083$; genotype $\times$ time interaction, $F_{(11,440)}=3.415, p=0.0001 ; n=11 \mathrm{cHet}$ and 10 control; genotype effect, $F_{(1,19)}=5.657, p<0.0001$; time effect, $F_{(11,209)}=$ $1.03, p=0.4207$; genotype $\times$ time interaction, $F_{(11,209)}=1.409$, $p=0.1704)$. These data suggest that these mice experienced reduced anxiety. To further assess anxiety, we evaluated mice in the elevated plus maze task (Fig. $3 D-F$ ) and found that both the R579W and cHet mice spent significantly more total time (twoway repeated-measures ANOVA with protected Fisher's LSD tests; $n=12$ R579W and 12 control; genotype effect, $F_{(1,22)}=$ $3.415, p=0.0781$; arm effect, $F_{(1,22)}=1.372, p=0.2539$; genotype $\times$ arm interaction, $F_{(1,22)}=7.013, p=0.0147 ;$ R579W vs control in open arms, $t_{(44)}=2.945, p=0.0041 ; n=11 \mathrm{cHet}$ and 10 control; genotype effect, $F_{(1,19)}=1.131, p=0.3010$; arm effect, $F_{(1,19)}=27.58, p<0.0001$; genotype $\times$ arm interaction, $F_{(1,19)}=11.13, p=0.0035$; cHet vs control in open arms, $t_{(38)}=$ $3.082, p=0.0038$ ) and a higher percentage of time (unpaired two-sample $t$ tests; $n=12$ R579W and 12 control; $t_{(22)}=2.846$, $p=0.0094 ; n=11 \mathrm{cHet}$ and 10 control; $\left.t_{(19)}=3.25, p=0.0042\right)$ in the open arms (Fig. $3 D, E$ ). We also found that, in both models, the mutants made significantly more entries into the open arm than the closed arm compared with controls (Fig. 3F; two-way repeatedmeasures ANOVA with protected Fisher's LSD tests; $n=12$ R579W and 12 control; genotype effect, $F_{(1,22)}=0.03982, p=0.8437$; entries effect, $F_{(1,22)}=0.6828, p=0.4175$; genotype $\times$ entries interaction, $F_{(1,22)}=12.82, p=0.0017$; open arm R579W vs control, $t_{(44)}=2.551, p=0.0143 ; n=11 \mathrm{cHet}$ and 10 control; genotype effect, $F_{(1,19)}=0.04737, p=0.8301$; entries effect, $F_{(1,19)}=$ $36.98, p<0.0001$; genotype $\times$ entries interaction, $F_{(1,19)}=22.37$, $p=0.0001$; open arm cHet vs control, $\left.t_{(38)}=2.075, p=0.0448\right)$. The increased time and entries made into the open arms by R579W and cHet mice were not a result of hyperactivity because the R579W and cHet mice made a similar number of arm entries as their respective littermate controls (R579W, $26 \pm 3$; R579W controls, $25 \pm 1$; cHet, $22 \pm 3$; cHet controls, $21 \pm 2$ ). Collectively, these data suggest that both the R579W and cHet mice are hyperactive and have reduced anxiety and/or a propensity for risky behavior. 

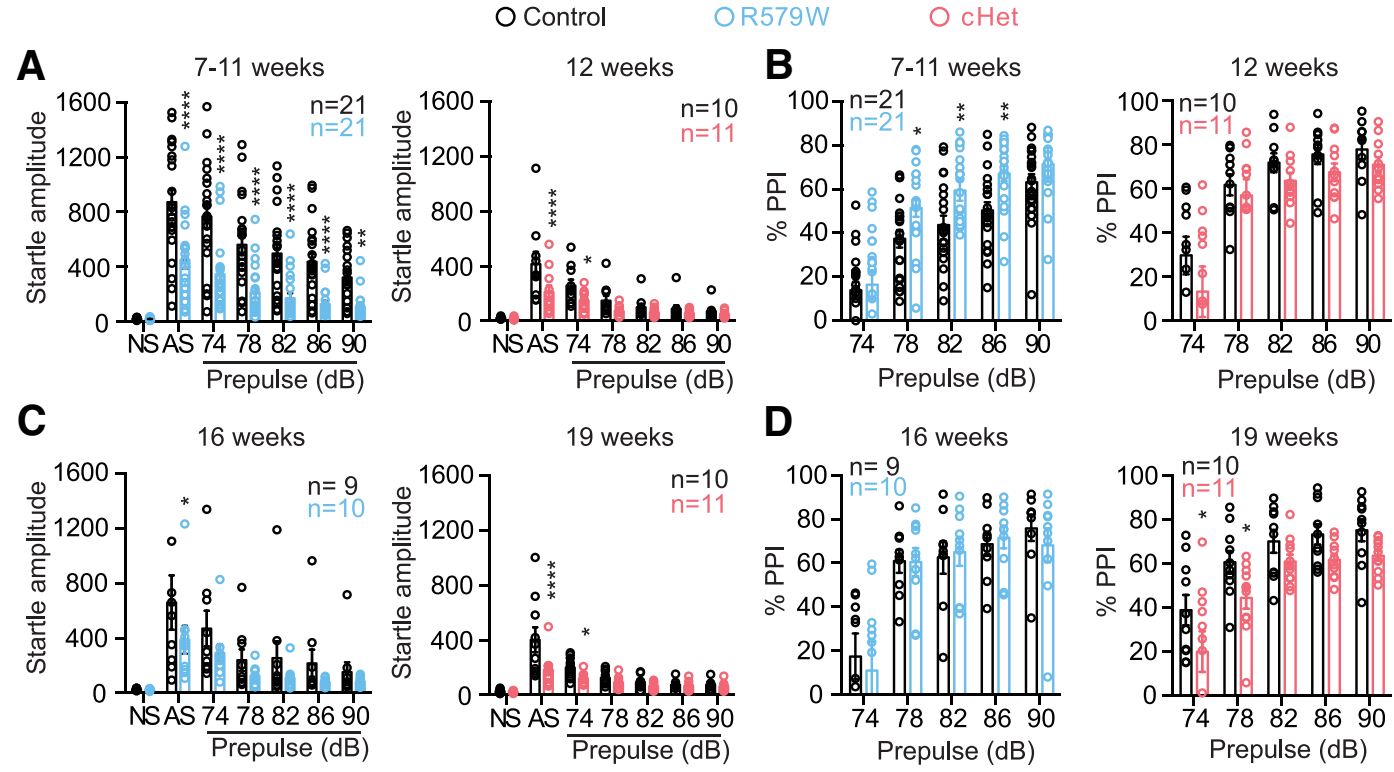

Figure 4. TCF4 mutant mice have an impaired startle response. Mice were tested for auditory function, reactivity to environmental stimuli, and sensorimotor gating by the acoustic startle test at 7-12 weeks of age $(\boldsymbol{A}, \boldsymbol{B})$ and $16-19$ weeks of age $(\boldsymbol{C}, \boldsymbol{D})$. $\boldsymbol{A}$, Response to acoustic startle (AS: $120 \mathrm{~dB})$ alone or in combination with a prepulse sound level $(74,78,82,86$, or $90 \mathrm{~dB}) . \boldsymbol{B}$, Percentage of prepulse inhibition (PPI). C, D, Startle amplitude (C) and \%PPI (D) upon retest at 16-19 weeks of age. Note that only one cohort of data from R579W mice and controls is shown for the second acoustic startle test at 16 weeks. Data represent individual data points and mean \pm SEM. Protected Fisher's LSD tests following significant ANOVA effects: ${ }^{*} p \leq 0.05,{ }^{* *} p \leq 0.01,{ }^{* * * *} p \leq 0.0001$.

\section{Reduced startle magnitude but enhanced sensorimotor gating in PTHS model mice}

Sensorimotor gating is often impaired in neuropsychiatric and neurodevelopmental disorders and can be assessed in mice by the auditory prepulse inhibition task. Accordingly, we measured auditory function, reactivity to environmental stimuli, and sensorimotor gating in an acoustic startle task. The R579W displayed highly significant decreases in the startle amplitude across a range of sound levels at 7-11 weeks of age (two-way repeated-measures ANOVA; $n=21$ R579W and 21 control; genotype effect, $F_{(1,40)}=$ 19.72, $p<0.0001$; amplitude effect, $F_{(6,240)}=92.57, p<0.0001$; genotype $\times$ amplitude interaction, $\left.F_{(6,240)}=10.97, p<0.0001\right)$, but only mild deficits to the acoustic startle stimulus alone by 16 weeks of age (two-way repeated-measures ANOVA; $n=10$ R579W and 9 control; genotype effect, $F_{(1,17)}=1.773, p=$ 0.2006 , amplitude effect, $F_{(6,102)}=21.27, p<0.0001$; genotype $\times$ amplitude interaction, $\left.F_{(6,102)}=1.316, p=0.2566\right)$, indicating a dampened response with age in this model (Fig. $4 A, C$ ). Reduced startle to a $74 \mathrm{~dB}$ stimulus was observed in cHet mice at both 12 and 19 weeks of age (Fig. 4A,C: two-way repeated-measures ANOVA; 12 weeks of age: $n=11$ R579W and 10 control; genotype effect, $F_{(1,19)}=5.461, p=0.0306$; amplitude effect, $F_{(6,114)}=$ $27.75, p<0.0001$; genotype $\times$ amplitude interaction, $F_{(6,114)}=$ $3.169, p=0.0065$; 19 weeks of age: $n=11$ R579W and 10 control; genotype effect, $F_{(1,19)}=6.259, p=0.0217$; amplitude effect, $F_{(6,114)}=26.59, p<0.0001$; genotype $\times$ amplitude interaction, $\left.F_{(6,114)}=4.985, p=0.0001\right)$. The percentage prepulse inhibition was significantly enhanced in 7 - to 11 -week-old but not 16 -weekold R579W mice (Fig. 4B,D; two-way repeated-measures ANOVA; 7-11 weeks of age: $n=21$ R579W and 21 control; genotype effect, $F_{(1,39)}=4.837, p=0.0339$; amplitude effect, $F_{(4,156)}=144.5, p<0.0001$; genotype $\times$ amplitude interaction, $F_{(4,156)}=3.238, p=0.0139 ; 16$ weeks of age: $n=10 \mathrm{R} 579 \mathrm{~W}$ and 9 control; genotype effect, $F_{(1,17)}=0.03478, p=0.8543$; amplitude effect, $F_{(4,68)}=66.92, p<0.0001$, genotype $\times$ amplitude interaction, $\left.F_{(4,76)}=0.7356, p<0.0001\right)$. This same measure was decreased in 19-week-old but not 12-week-old cHet mice (Fig.
$4 B, D$; two-way repeated-measures ANOVA; 12 weeks of age: $n=$ $11 \mathrm{cHet}$ and 10 control; genotype effect, $F_{(1,19)}=1.64, p=$ 0.2157 ; amplitude effect, $F_{(4,76)}=51.38, p<0.0001$; genotype $\times$ amplitude interaction, $F_{(4,76)}=0.5385, p=0.7078 ; 19$ weeks of age: $n=11$ mutant and 10 control; genotype effect, $F_{(1,19)}=$ 5.498, $p=0.0301$; amplitude effect, $F_{(4,76)}=39.21, p<0.0001$; genotype $\times$ amplitude interaction, $\left.F_{(4,76)}=0.5475, p=0.7013\right)$. Overall, these results indicate that R579W and cHet mice have modestly impaired startle responses and divergent sensorimotor gating phenotypes that each manifest in an age-dependent manner.

\section{Motor coordination and sociability appear normal in PTHS model mice}

PTHS individuals often exhibit motor impairments (de Pontual et al., 2009; de Winter et al., 2016) that can potentially affect other behaviors. These behaviors may include sociability, dysfunction of which is common in individuals with autism spectrum disorder but documented to be normal in PTHS individuals (Marangi and Zollino, 2015). In the accelerating rotarod test of motor function, the R579W and cHet mice had similar motor performance to their littermate controls (Fig. 5A; two-way repeated-measures ANOVA; $n=12$ R579W and 12 control; genotype effect, $F_{(1,22)}=$ $1.298, p=0.2668$; time effect, $F_{(4,88)}=15.98, p<0.0001$; genotype $\times$ time interaction, $F_{(4,88)}=0.607, p=0.6586 ; n=11 \mathrm{cHet}$ and 10 control; genotype effect, $F_{(1,19)}=0.1183, p=0.7347$, time effect, $F_{(4,76)}=13.99, p<0.0001$; genotype $\times$ time interaction, $\left.F_{(4,76)}=1.087, p=0.3691\right)$. This suggests that the mice exhibit normal motor performance and are thus physically capable of normal social interactions. To test for sociability, we measured mice in a three-chamber task. Both R579W and cHet mice and their littermate controls preferred the novel mouse chamber over the empty cage and, on average, spent significantly more time in the novel chamber (Fig. 5B; two-way repeated-measures ANOVA with protected Fisher's LSD tests; $n=10$ R579W and 9 control; genotype effect, $F_{(1,17)}=3.767, p=0.69$, object effect; $F_{(1,17)}=$ $47.68, p<0.0001$; genotype $\times$ object interaction, $F_{(1,17)}=1.578$, 


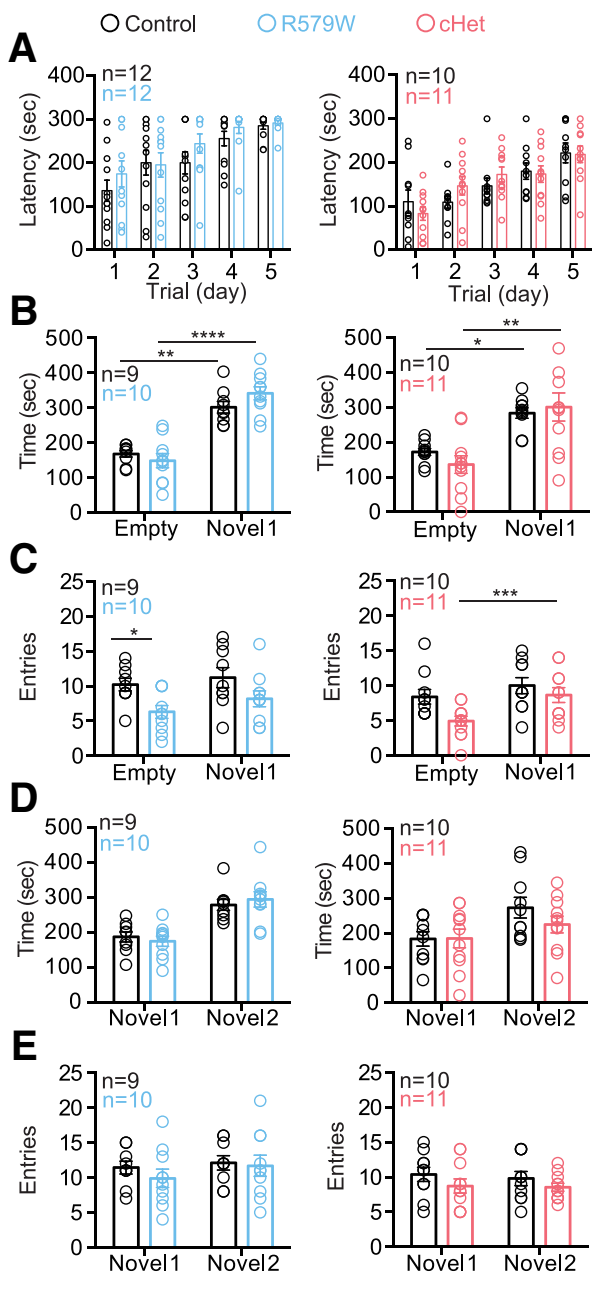

Figure 5. TCF4 mutant mice have typical motor coordination and social behavior. $A$, Latency to fall on an accelerating rotarod. $\boldsymbol{B}$, Amount of time the mice spent in either the empty chamber or the chamber housing a novel mouse (Novel 1) in a three-chambered assay. $\boldsymbol{C}$, Number of entries made into the empty versus occupied (Novel 1 ) chamber in the three-chambered assay. D, Time spent with either a now familiar (Novel 1) or a new mouse (Novel 2) in a threechambered assay. $\boldsymbol{E}$, Number of entries that each mouse made into the chamber housing either a now familiar mouse (Novel 1) or a novel mouse (Novel 2) in a three-chambered assay. Only data from the male R579W mice and control are presented for the three-chambered task due to high variability in the female mice. Data represent individual data points and mean \pm SEM. Protected Fisher's LSD tests following significant ANOVA effects: ${ }^{*} p \leq 0.05,{ }^{* *} p \leq 0.01$, ${ }^{* * *} p \leq 0.001,{ }^{* * *} p \leq 0.0001$.

$p=0.2260 ;$ R579W empty vs novel, $t_{(17)}=3.893, p=0.0012$; control empty vs novel, $t_{(17)}=5.629, p<0.0001 ; n=11 \mathrm{cHet}$ and 10 control; genotype effect, $F_{(1,19)}=0.5956 ; p=0.4497$, object effect; $F_{(1,19)}=15.97, p=0.0008$; genotype $\times$ object interaction, $F_{(1,19)}=0.5956, p=0.4497$; cHet empty vs novel, $t_{(19)}=2.227$; control empty vs novel, $\left.t_{(19)}=3.454, p=0.0027\right)$. Both R579W and cHet mice and their littermate controls made significantly more entries into the novel chamber than the empty chamber (Fig. 5C; two-way repeated-measures ANOVA with protected Fisher's LSD tests; $n=10$ R579W and 9 control; genotype effect, $F_{(1,17)}=7.026, p=0.0168$; object effect, $F_{(1,17)}=2.765, p=$ 0.1147 ; genotype $\times$ object interaction, $F_{(1,17)}=0.2663, p=$ 0.6124 ; R579W empty vs novel, $t_{(34)}=2.492, p=0.0177$; control empty vs novel, $t_{(34)}=1.921, p=0.0632 ; n=11 \mathrm{cHet}$ and 11 control; genotype effect, $F_{(1,19)}=3.838, p=0.0649$, object effect, $F_{(1,19)}=16.37, p=0.0007$; genotype $\times$ object interaction, $F_{(1,19)}=$ $2.61, p=0.1227$, cHet empty vs novel $t_{(19)}=1.679, p=0.0006$; control empty vs novel, $\left.t_{(19)}=4.102, p=0.1096\right)$. During the next phase, the mice were given the choice between the now-familiar mouse (Novel 1) and a novel mouse (Novel 2) (Fig. 5D,E). We found that, similar to their respective controls, R579W and cHet mice showed no strong preference for either novel test mouse (two-way repeated-measures ANOVA; time spent: $n=10$ R579W and 9 control; genotype effect; $F_{(1,17)}=0.03902, p=$ 0.8457 ; object effect, $F_{(1,17)}=21.84, p=0.0002$; genotype $\times$ object interaction; $F_{(1,17)}=0.3852, p=0.5430$; time spent: $n=$ $11 \mathrm{cHet}$ and 10 control; genotype effect, $F_{(1,19)}=1.322, p=$ 0.2645 ; object effect, $F_{(1,19)}=4.763, p=0.0418$; genotype $\times$ object interaction, $F_{(1,19)}=0.6869, p=0.4175$; entries: $n=10$ R579W and 9 control; genotype effect, $F_{(1,17)}=0.4395$, object effect, $F_{(1,17)}=1.635$, genotype $\times$ object interaction, $F_{(1,17)}=$ $1.635, p=0.2181 ; n=11 \mathrm{cHet}$ and 10 control; genotype effect, $F_{(1,19)}=1.666, p=0.2122$; object effect, $F_{(1,19)}=0.3849, p=$ 0.5423 ; genotype $\times$ object interaction, $F_{(1,19)}=0.3849, p=$ 0.5423). Given the hyperactive nature of the R579W and cHet mice, we assessed the number of entries into the chambers and found small, albeit significant, decreases in entry numbers compared with controls, but only after the first phase (Fig. $5 C, E)$. Overall, we found that the R579W and cHet mice display normal motor coordination and typical sociability.

\section{Spatial learning and memory are impaired in PTHS model mice}

We measured performance in the Morris water maze task to assess hippocampus-dependent spatial learning and memory. The R579W and cHet mice were able to locate the visible platform and largely had similar swim speeds during all phases of testing to their respective littermate controls (Table 1), suggesting that they had sufficient visual and motor skills to perform the task. However, both the R579W and cHet mice took a significantly longer time to locate the hidden platform than controls [Fig. 6A: twoway repeated-measures ANOVA; $n=21 \mathrm{R} 579 \mathrm{~W}$ and 21 control (cohort $1+2$ combined); genotype effect, $F_{(1,40)}=14.3, p=$ 0.0005 , time effect, $F_{(2,80)}=6.373, p=0.0027$, genotype $\times$ time interaction, $F_{(2,80)}=0.9883, p=0.3767 ; n=9$ R579W and 9 control (cohort 2 only); genotype effect, $F_{(1,16)}=3.348, p=$ 0.0860 , time effect, $F_{(4,64)}=3.706, p=0.0089$, genotype $\times$ time interaction: $F_{(4,64)}=6.373, p=0.0699 ; n=11 \mathrm{cHet}$ and 10 control; genotype effect, $F_{(1,19)}=7.667, p<0.0001$, time effect, $F_{(4,76)}=9.794, p<0.0001$, genotype $\times$ time interaction, $F_{(4,76)}=$ $1.512, p=0.0122]$. Consistent with the finding of hyperactivity in the open field (Fig. 3), cHet and R579W mutant mice traveled farther during the acquisition phase than controls [Figure $6 B$ : two-way repeated-measures ANOVA; $n=21 \mathrm{R} 579 \mathrm{~W}$ and 21 control (cohort $1+2$ combined); genotype effect, $F_{(1,40)}=19.69$, $p<0.0001$, time effect, $F_{(2,80)}=8.406, p=0.0005$, genotype $\times$ time interaction, $F_{(2,80)}=0.8411, p=0.4350 ; n=9$ R579W and 9 control (cohort 2 only); genotype effect, $F_{(1,16)}=4.755, p=$ 0.0455 , time effect, $F_{(4,64)}=4.639, p=0.0024$, genotype $\times$ time interaction, $F_{(4,64)}=2.22, p=0.0766 ; n=11 \mathrm{cHet}$ and 10 control; genotype effect, $F_{(1,19)}=8.194, p=0.01$, time effect, $F_{(4,76)}=9.669, p<0.0001$, genotype $\times$ time interaction, $F_{(4,76)}=$ $1.787, p=0.1401$ ]. Interestingly, during the reversal phase of the hidden platform test, the R579W performed comparably to controls, yet the cHet mice never met criterion (15 s) for learning across the entire $8 \mathrm{~d}$ regimen [Figure 6C; two-way repeatedmeasures ANOVA; $n=21 \mathrm{R} 579 \mathrm{~W}$ and 21 control (cohort $1+2$ combined); genotype effect, $F_{(1,40)}=0.8178$, time effect, $F_{(2,80)}=$ $1.468, p=0.2366$, genotype $\times$ time interaction, $F_{(2,80)}=1.468$, $p=0.2366 ; n=9 \mathrm{R} 579 \mathrm{~W}$ and 9 control (cohort 2 only); genotype 


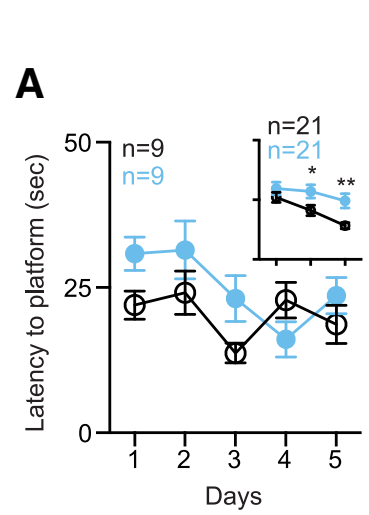

B

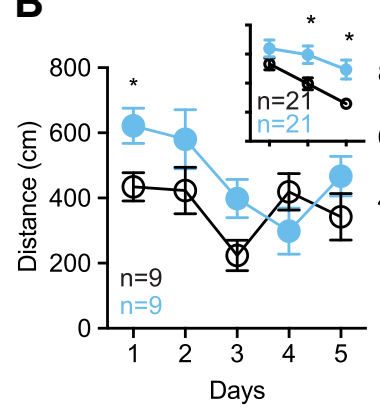

O Control

- R579W $\mathrm{cHet}$

C
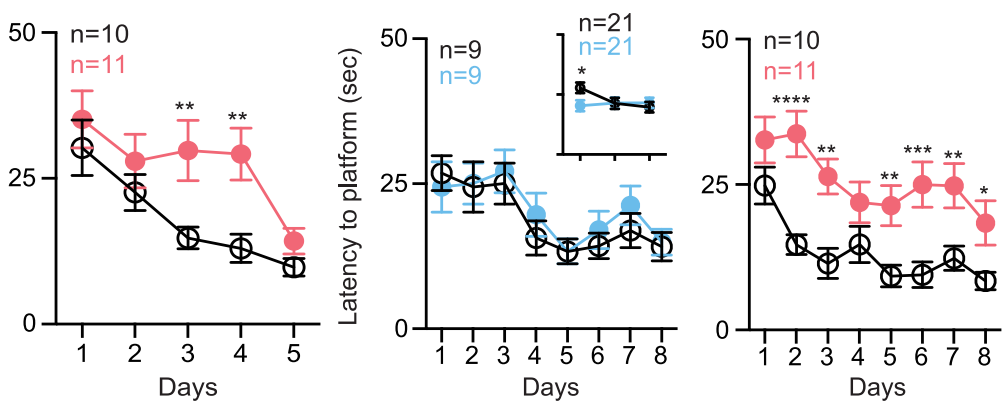

D
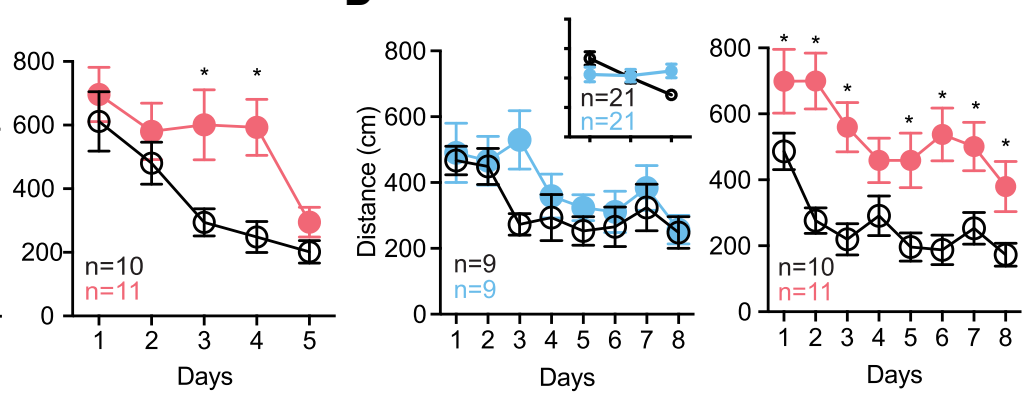

Figure 6. PTHS model mice exhibit hippocampus-dependent spatial learning and memory deficits. $A$, Latency to find a hidden platform during training in the Morris water maze task. $B$, Distance traveled during hidden platform training. C, Latency to find a hidden platform in a reversal learning task in which the platform is placed in a new location. $\boldsymbol{D}$, Distance traveled during reversal learning task. Insets in $\boldsymbol{A}-\boldsymbol{D}$ represent the combined data for the first $3 \mathrm{~d}$ from 2 cohorts of R579W and control mice. Data represent mean \pm SEM. Protected Fisher's LSD tests following significant ANOVA effects: ${ }^{*} p \leq 0.05,{ }^{* *} p \leq 0.01,{ }^{* * *} p \leq 0.001,{ }^{* * * *} p \leq 0.0001$.

Table 1. Swimming distance and velocity in the Morris water maze

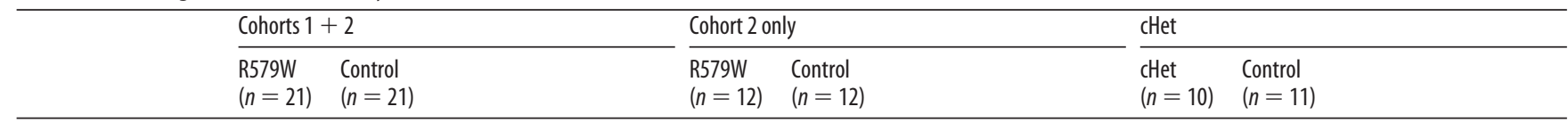

Visible platform,

distance $(\mathrm{cm})$

Day 1

Day 2

Swim speed $(\mathrm{cm} / \mathrm{s})$

Day 1: Visible platform

Day 1: Acquisition

Day 1: Reversal

\begin{abstract}
$349 \pm 27 \quad 347 \pm 25 \quad t_{(40)}=0.0544 ; p=0.9569 \quad 311 \pm 33 \quad 334 \pm 33 \quad t_{(22)}=0.4928 ; p=0.6270 \quad 334 \pm 54 \quad 414 \pm 35 \quad t_{(19)}=1.2664 ; p=0.2207$ $177 \pm 35229 \pm 30 \quad t_{(40)}=1.1280 ; p=0.2660 \quad 270 \pm 49 \quad 194 \pm 57 \quad t_{(22)}=1.011 ; p=0.3230 \quad 135 \pm 20 \quad 198 \pm 45 \quad t_{(19)}=1.2356 ; p=0.2317$

$15 \pm 0.7 \quad 17 \pm 0.5 \quad t_{(40)}=2.3250 ; p=0.0252^{*} \quad 17 \pm 0.8 \quad 17 \pm 0.7 \quad t_{(22)}<0.001 ; p>0.999$

$21 \pm 0.520 \pm 0.6 \quad t_{(40)}=1.2804 ; p=0.2078 \quad 22 \pm 0.6 \quad 20 \pm 0.5 \quad t_{(22)}=2.5607 ; p=0.0178^{*}$

$20 \pm 0.6 \quad 19 \pm 0.7 \quad t_{(40)}=1.0847 ; p=0.2846 \quad 20 \pm 0.8 \quad 20 \pm 0.5 \quad t_{(22)}<0.001 ; p>0.999$

$17 \pm 0.5 \quad 18 \pm 0.4 \quad t_{(19)}=1.5754 ; p=0.1317$

$20 \pm 0.5 \quad 20 \pm 0.4 \quad t_{(19)}<0.0001 ; p>0.9999$

$21 \pm 0.9 \quad 19 \pm 0.7 \quad t_{(19)}=1.7719 ; p=0.0925$
\end{abstract}

Data are shown as means \pm SEM of four trials per day. Distance measures are shown for the $2 \mathrm{~d}$ visible platform test. Swim speeds are given for day 1 of each phase of testing. ${ }^{*} p<0.05$.

effect, $F_{(1,16)}=0.4242, p=0.5241$; time effect, $F_{(7,112)}=6.374$, $p<0.0001$; genotype $\times$ time interaction, $F_{(7,112)}=0.2958, p=$ $0.9543 n=11 \mathrm{cHet}$ and $10 \mathrm{control}$; genotype effect, $F_{(1,19)}=$ 24.42, $p<0.0001$; time effect, $\mathrm{F}_{(7,133)}=p<0.0001$; genotype $\times$ time interaction, $\left.\mathrm{F}_{(7,133)}=1.032, p=0.4122\right]$. In terms of distance traveled during the reversal phase, cHet but not R579W mutant mice traveled farther than controls [Figure 6D: two-way repeated-measures ANOVA; $n=21 \mathrm{R} 579 \mathrm{~W}$ and 21 control (cohort $1+2$ combined); genotype effect, $F_{(1,40)}=0.4165, p=$ 0.5224 , time effect, $F_{(2,80)}=3.666, p=0.0300$, genotype $\times$ time interaction, $F_{(2,80)}=5.364, p=0.0065 ; n=9$ R579W and 9 control (cohort 2 only); genotype effect, $F_{(1,16)}=1.588, p=$ 0.2256 , time effect, $F_{(4,64)}=5.039, p<0.0001$, genotype $\times$ time interaction, $F_{(4,64)}=1.156, p=0.3341 ; n=11 \mathrm{cHet}$ and 10 control; genotype effect, $F_{(1,19)}=24.84, p<0.0001$, time effect, $F_{(4,76)}=5.649, p<0.0001$, genotype $\times$ time interaction, $F_{(4,76)}=$ 1.094, $p=0.3707]$. Together, these data show that, although there may be subtle genotype-phenotype differences, both the
R579W and cHet mice have deficits in spatial learning and memory.

\section{Hippocampal long-term potentiation is enhanced in four mouse models of PTHS}

Given that both the R579W and cHet mice show learning deficits in the Morris water maze (Fig. 6), we determined whether hippocampal synaptic function was disrupted in the PTHS mouse models. We first measured basic properties of synaptic transmission by recording CA1 field EPSPs (fEPSPs) evoked by Schaffer collateral stimulation. The resulting I/O curves showed that AMPA receptor (AMPAR)-mediated synaptic transmission was normal in all four PTHS mouse models relative to their respective control littermates (Fig. 7A1-A4; two-way repeated-measures ANOVA; $n=31$ R579W and 32 control; genotype effect, $F_{(1,61)}=$ $0.009042, p=0.9246$; current effect, $F_{(12,732)}=116.0, p<0.0001$; genotype $\times$ current interaction, $F_{(12,732)}=1.087, p=0.3679 ; n=$ $28 \mathrm{cHet}$ and 26 control; genotype effect, $F_{(1,52)}=0.01123, p=$ 
A1

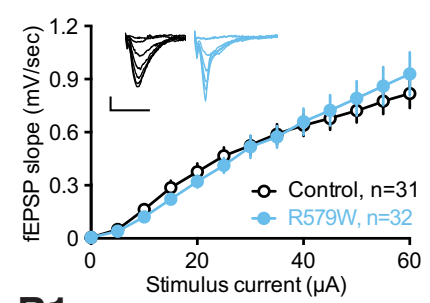

B1

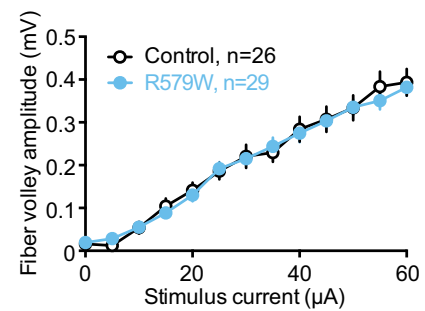

C1

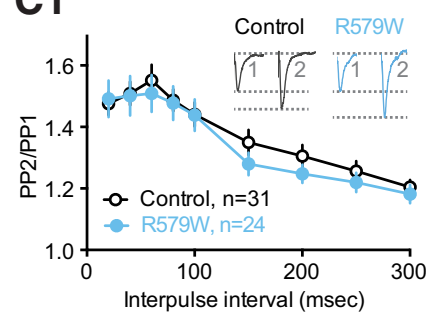

A2

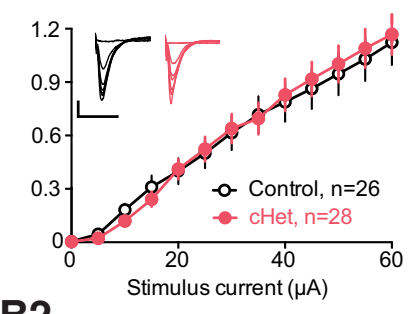

B2

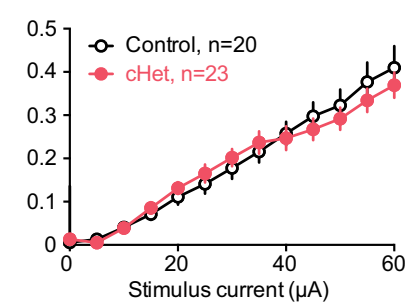

C2

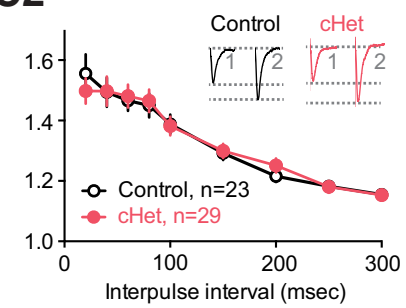

A3

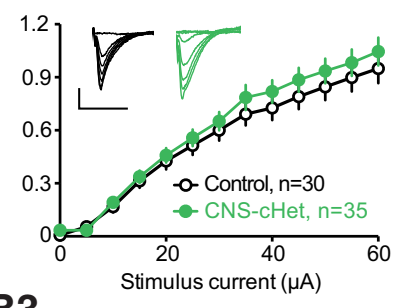

B3

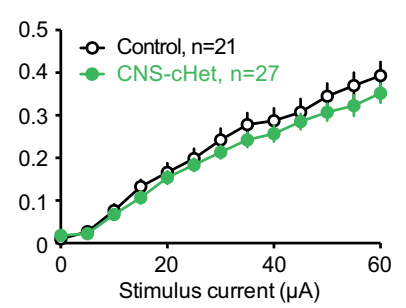

C3

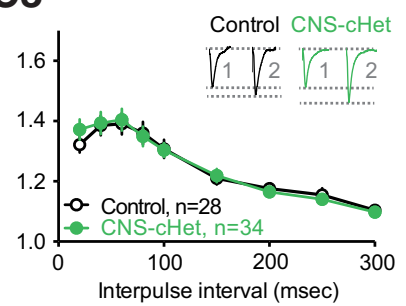

A4

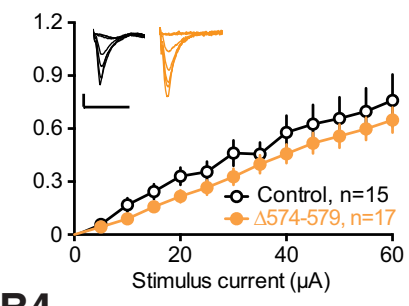

B4

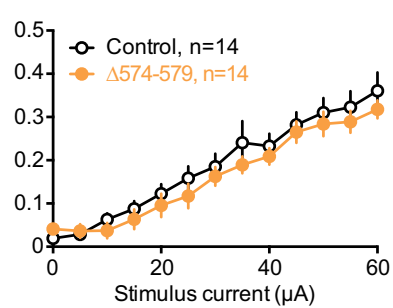

C4

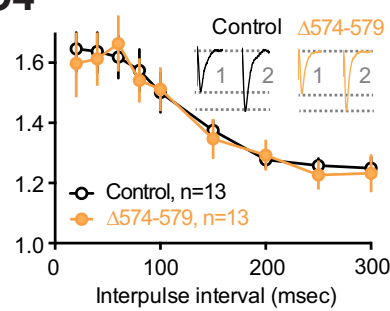

Figure 7. Synaptic transmission and short-term plasticity are normal in PTHS mouse models. Extracellular field recordings from hippocampal area CA1 and evoked by Schaffer collateral stimulation. (A) I/O curves for R579W (A1), CHet (A2), CNS-CHet (A3), and $\Delta 574-579$ (A4) mice relative to control littermates. Insets in $\boldsymbol{A}$ show representative responses during generation of I/0 characteristics. (B), Fiber volley responses for R579W (B1), CHet (B2), CNS-CHet (B3), and $\Delta 574-579$ (B4) mice relative to control littermates. (C) Paired-pulse ratio (PP2/PP1) for R579W (C1), CHet (C2), CNS-CHet (C3), and $\Delta 574-579$ (C4) mice relative to control littermates. Insets in C show representative paired-pulse responses with a $60 \mathrm{~ms}$ interpulse interval. Scale bar, $5 \mathrm{~ms} 0.25 \mathrm{mV}$.

0.9160 ; current effect, $F_{(12,624)}=126.3, p<0.0001$; genotype $\times$ current effect, $F_{(12,624)}=0.3997, p=0.9638 ; n=35$ CNS-cHet and 30 control; genotype effect, $F_{(1,63)}=0.7331, p=0.3951$; current effect, $F_{(12,756)}=224.9, p<0.0001$; genotype $\times$ current interaction, $F_{(12,756)}=0.6985, p=0.7539 ; n=17 \Delta 574-579$ and 15 control; genotype effect, $F_{(1,30)}=1.336, p=0.2569$; current effect, $F_{(12,360)}=64.56, p<0.0001 ; F_{(12,360)}=0.5086, p=$ $0.9091)$. Presynaptic function also appeared normal in PTHS model mouse in terms of the presynaptic fiber volley (Fig. 7B1$B 4$; two-way repeated-measures ANOVA; $n=29$ R579W and 26 control; genotype effect, $F_{(1,53)}=0.02714, p=0.8698$; current effect, $F_{(12,636)}=223.1, p<0.0001$; genotype $\times$ current interaction, $F_{(12,636)}=0.5708, p=0.8633 ; n=23 \mathrm{cHet}$ and 20 control; genotype effect, $F_{(1,41)}=0.02937, p=0.8777$; current effect, $F_{(12,492)}=105.8, p<0.0001$; genotype $\times$ current interaction, $F_{(12,492)}=0.9958, p=0.4516 ; n=27$ CNS-cHet and 21 control; genotype effect, $F_{(1,46)}=0.9902, p=0.3249$; current effect, $F_{(12,552)}=219.2, p<0.0001$; genotype $\times$ current interaction, $F_{(12,552)}=0.9564, p=0.4899 ; n=14 \Delta 574-579$ and 14 control; genotype effect, $F_{(1,26)}=1.295, p=0.2656$; current effect, $F_{(12,312)}=135.2, p<0.0001$; genotype $\times$ current interaction, $\left.F_{(12,312)}=1.053, p=0.4000\right)$. In addition, short-term plasticity appeared normal in PTHS model mice in terms of the pairedpulse ratio (Fig. 7C1-C4; two-way repeated-measures ANOVA; $n=24$ R579W and 31 control; genotype effect, $F_{(1,53)}=0.2462$, $p=0.6218$; interval effect, $F_{(8,424)}=62.25, p<0.0001$; genotype $\times$ interval interaction, $F_{(8,424)}=0.7348, p=0.6608 ; n=23$ cHet and 29 control; genotype effect, $F_{(1,50)}=0.008154, p=$ 0.9773 ; interval effect, $F_{(8,400)}=73.82, p<0.0001$; genotype $\times$ interval interaction, $F_{(8,400)}=0.5870, p=0.7887 ; n=34$ CNScHet and 28 control; genotype effect, $F_{(1,60)}=0.0127, p=0.9106$; interval effect, $F_{(8,480)}=100.9, p<0.0001$; genotype $\times$ interval interaction, $F_{(8,480)}=0.832, p=0.5747 ; n=13 \Delta 574-579$ and 13 control; genotype effect, $F_{(1,24)}=0.02017, p=0.8883$; interval effect, $F_{(8,192)}=64.96, p<0.0001$; genotype $\times$ interval effect, $\left.F_{(8,192)}=0.4969, p=0.8575\right)$. Together, these findings indicate that presynaptic function and AMPAR-mediated synaptic transmission appear grossly normal in hippocampal area CA1 in four PTHS mouse models.

To determine whether Tcf4 mutations alter hippocampal synaptic plasticity, we measured the long-term changes in synaptic strength in response to stimulation patterns known to induce either LTP or LTD. We found significant enhancement of LTP after $31 \mathrm{~s}$ bursts of $100 \mathrm{~Hz}$ stimulation (separated by $20 \mathrm{~s}$ ) in each of the mutant models compared with littermate controls (Fig. 8A1-A4; unpaired two-sample $t$ tests; $n=10$ R579W and 10 control; $t_{(18)}=2.3720, p=0.0290 ; n=10 \mathrm{cHet}$ and 8 control; $t_{(16)}=2.2434, p=0.0394 ; n=12 \mathrm{CNS}$-cHet and 11 control; $t_{(21)}=$ 2.0817, $p=0.0498 ; n=11 \Delta 574-579$ and 10 control; $t_{(19)}=$ $2.6588, p=0.0155)$. However, no significant differences in LTD after $15 \mathrm{~min}$ of $1 \mathrm{~Hz}$ stimulation were established among any of the PTHS mouse models compared with controls (Fig. 8B1-B4; unpaired two-sample $t$ tests; $n=6$ R579W and 7 control; $t_{(11)}=$ $0.1949, p=0.8491 ; n=7 \mathrm{cHet}$ and 6 control; $t_{(11)}=0.8912, p=$ $0.3919 ; n=6$ CNS-cHet and 8 control; $t_{(12)}=0.5434, p=0.5968$; $n=6 \Delta 574-579$ and 6 control; $\left.t_{(10)}=0.7688, p=0.4598\right)$. The enhanced LTP was not limited to strong induction protocols because we found that LTP was consistently enhanced in all PTHS 
A1

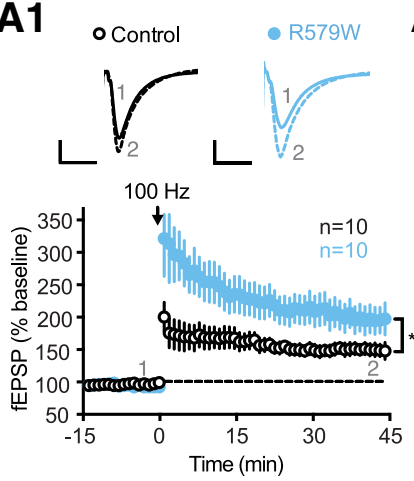

\section{B1}
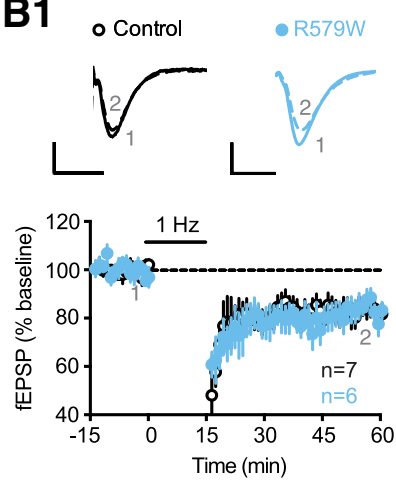

C1

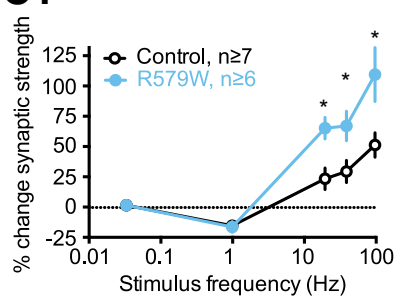

A2

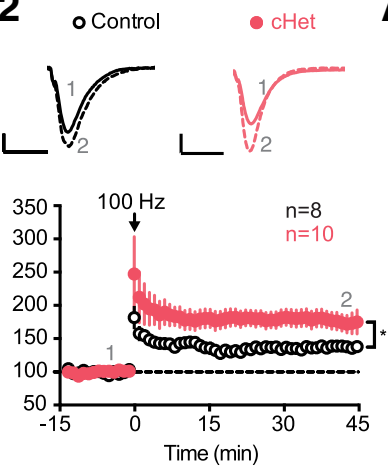

B2
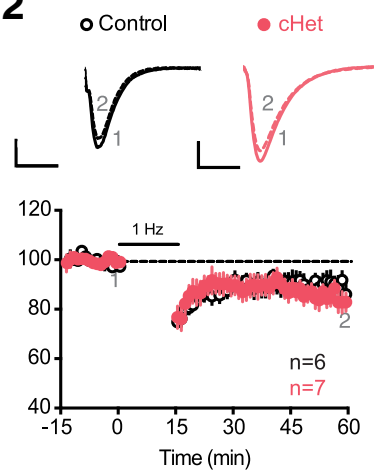

C2

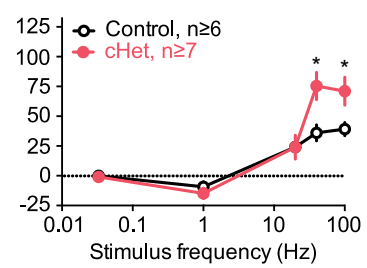

A3

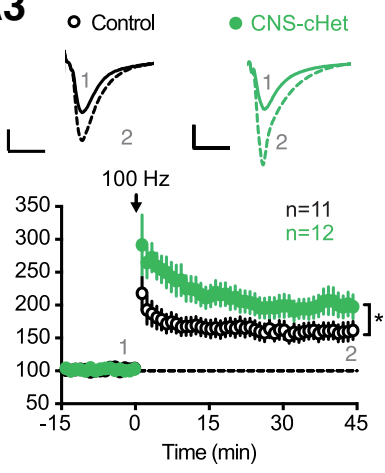

B3
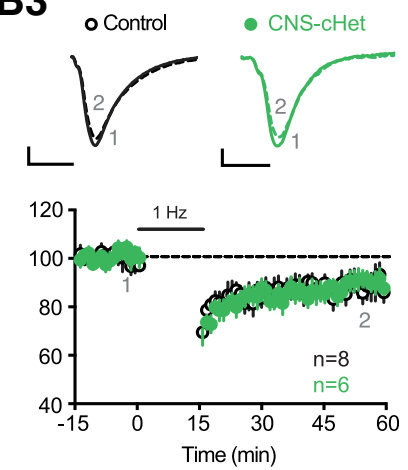

C3

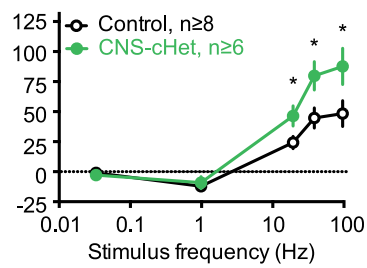

A4

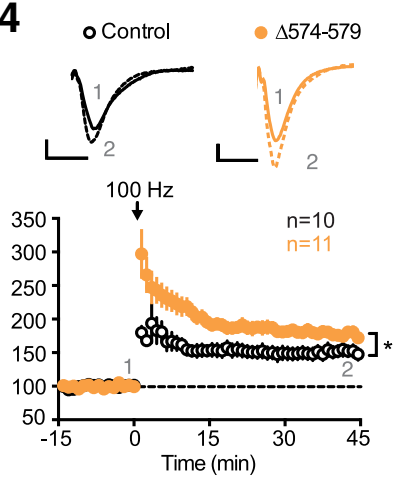

B4
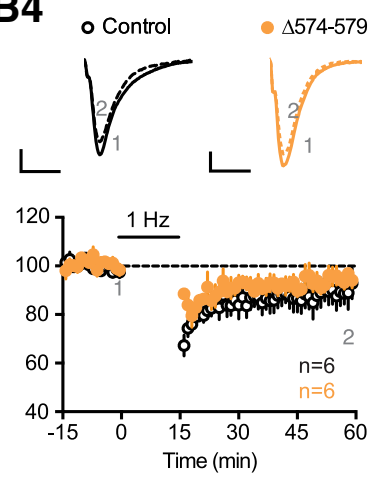

C4

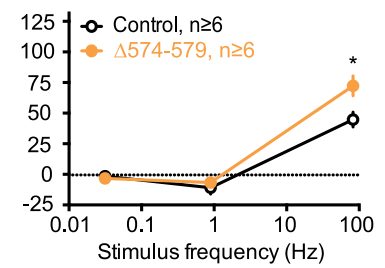

Figure 8. Consistent enhancement of hippocampal LTP in PTHS model mice. (A) LTP of fEPSP slope induced by 3, 1 s bursts at $100 \mathrm{~Hz}$ separated by 20 Hz for R579W (A1), CHet (A2), CNS-CHet (A3), and $\Delta 574-579$ (A4) mice relative to control littermates. Top, Representative traces scale bars, $5 \mathrm{~ms} 0.25 \mathrm{mV}$. (B) LTD of fEPSP slope induced by $1 \mathrm{~Hz}$ stimulation for $15 \mathrm{~min}$ for R579W (B1), CHet (B2), CNS-CHet (B3), and $\Delta 574-579$ (B4) mice relative to control littermates. Representative trace scale bars: $5 \mathrm{~ms} 0.25 \mathrm{mV}$. (C) Frequency-response curves generated across a range of stimulation frequencies for R579W (C1), CHet (C2), CNS-CHet (C3), and $\Delta 574-579$ (C4) mice relative to control littermates. Data show mean \pm SEM. ${ }^{*} p<0.05$.

mouse models over a range of stimulation frequencies (Fig. $8 \mathrm{C} 1-$ C4; unpaired two-sample $t$ tests; R579W: $20 \mathrm{~Hz}, t_{(13)}=3.2841$, $p=0.0059,40 \mathrm{~Hz}, t_{(14)}=2.4801, p=0.0265$; cHet: $20 \mathrm{~Hz}, t_{(12)}=$ $0.0137, p=0.9893,40 \mathrm{~Hz}, t_{(15)}=3.4494, p=0.0036$; CNS-cHet, $20 \mathrm{~Hz}, t_{(12)}=2.2721, p=0.0423,40 \mathrm{~Hz}, t_{(16)}=2.1246, p=$ $0.0491)$. Collectively, these data show that enhanced LTP is a highly penetrant feature of PTHS mouse models.

\section{NMDA receptor hyperfunction and intrinsic firing properties in $\mathrm{R} 579 \mathrm{~W}$ and cHet mice}

The enhanced LTP in all four PTHS mouse models was striking and warranted a deeper look at underlying intrinsic membrane properties and receptor-mediated transmission to gain mechanistic insights. Given the consistent hippocampus-dependent behavioral phenotypes and the intensive nature of whole-cell recordings, we focused on the R579W and cHet mouse models for further analysis of CA1 pyramidal neurons.

We found that CA1 pyramidal neurons from R579W mice and control littermates had similar RMPs (Fig. 9A; unpaired two-sample $t$ test; $n=18$ R579W and 14 control; $\left.t_{(30)}=0.1775, p=0.8603\right)$. Furthermore, at a series of holding potentials $(-75 \mathrm{mV},-70 \mathrm{mV}$, and $-65 \mathrm{mV}$ ), there were no statistically significant differences be- tween neurons from R579W mutants and controls in input resistance (Fig. 9B; two-way repeated-measures ANOVA; $n=14$ R579W and 13 control; genotype effect, $F_{(1,25)}=1.662, p=0.2013$; potential effect, $F_{(2,75)}=14.31, p<0.0001$; genotype $\times$ potential interaction, $\left.F_{(2,75)}=1.001, p=0.3724\right)$, nor were there differences in subthreshold responses to the application of a hyperpolarizing current injection (Fig. 9C; two-way repeated-measures ANOVA; $n=14$ R579W and 13 control; genotype effect, $F_{(1,25)}=3.185 ; p=0.0783$, potential effect, $F_{(2,75)}=1.722, p=0.1858$; genotype $\times$ potential interaction, $\left.F_{(2,75)}=0.01825, p=0.9819\right)$ and cessation of a hyperpolarizing current injection (rebound, Fig. 9D; two-way repeated-measures ANOVA; $n=14$ R579W and 13 control; genotype effect, $F_{(1,25)}=$ $1.546, p=0.2177$; potential effect, $F_{(2,75)}=0.6843, p=0.5076$, genotype $\times$ potential interaction, $\left.F_{(2,75)}=0.5827, p=0.4192\right)$. In addition, we found no statistical differences in the membrane time constant between groups at a holding potential of $-70 \mathrm{mV}$ ( $\tau_{\mathrm{m}}$, Fig. 9E; unpaired two-sample $t$ tests; $n=14 \mathrm{R} 579 \mathrm{~W}$ and 13 control; -400 pA: $t_{(21)}=1.576, p=0.1299 ;+400$ pA: $t_{(21)}=$ $0.9253)$. Therefore, passive membrane properties of CA1 pyramidal neurons were largely unaffected by the R579W mutation.

When we investigated whether there were changes in intrinsic firing properties of CA1 pyramidal neurons, we found unexpect- 
A

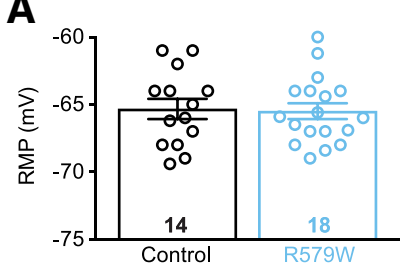

B

D

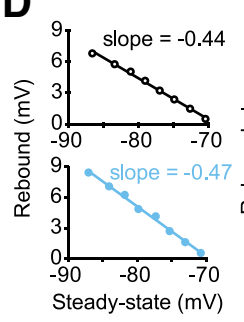

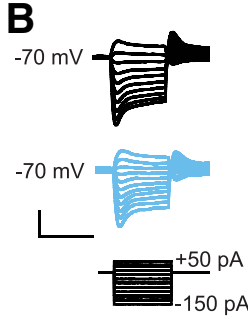
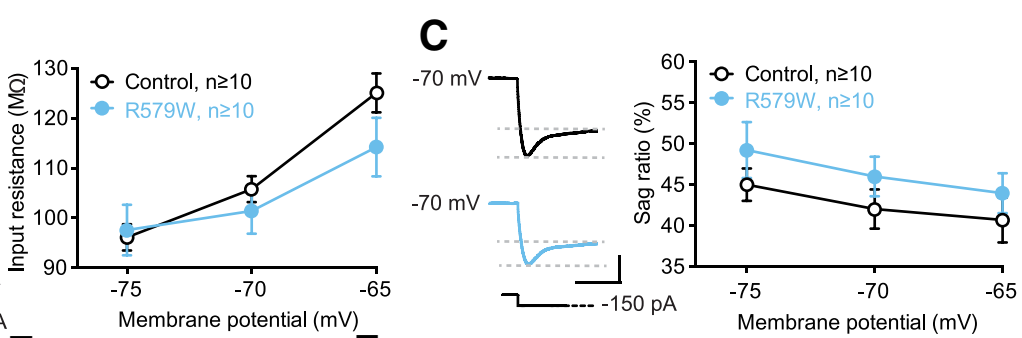

\section{$E$}
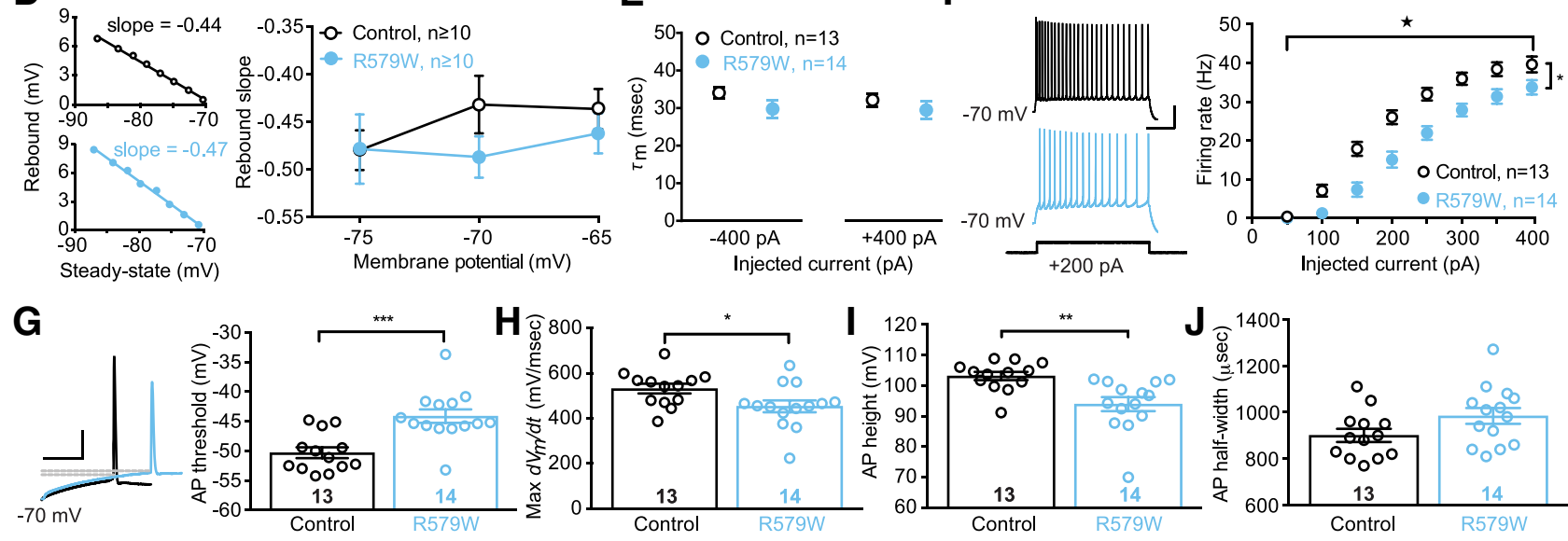

Figure 9. The R579W mutation alters active membrane properties in CA1 pyramidal neurons. Current-clamp measurements from CA1 pyramidal cells from R579W mice and control littermates of passive properties $(\boldsymbol{A}-\boldsymbol{D})$ and intrinsic excitability and action potential features $(\boldsymbol{E}-\boldsymbol{I})$. $\boldsymbol{A}, \mathrm{RMP}$. $\boldsymbol{B}$, Averaged input resistance. Sample trace scale bars: $500 \mathrm{~ms} \times 10 \mathrm{mV}$. $\boldsymbol{C}$, Sag ratio. Sample trace (150 pA injection) scale bars, $250 \mathrm{~ms} \times 10 \mathrm{mV}$. D, Rebound slope. Left, Representative rebound slope examples based on rebound/steady-state voltage relationship. $\boldsymbol{E}$, Membrane time constant $\tau_{\mathrm{m}}$ measured from hyperpolarizing $(-400 \mathrm{pA})$ or depolarizing $(+400 \mathrm{pA})$ current steps. $\boldsymbol{F}$, Action potential firing rate to a depolarizing $(200 \mathrm{pA})$ current step. Sample trace scale bar, $250 \mathrm{~ms} \times 25 \mathrm{mV}$. $\mathbf{G}$, Firing threshold. Left, Example action potentials. Scale bar, $20 \mathrm{~ms} \times 25 \mathrm{mV}$. Right, Membrane voltage at which action potentials are initiated $\left(d V_{\mathrm{m}} / d t=20\right)$. $\boldsymbol{H}-\boldsymbol{J}, \mathbf{M a x i m u m}$ action potential $d V_{\mathrm{m}} / d t(\boldsymbol{H})$, height $(\boldsymbol{I})$, and half-width $(\boldsymbol{J})$. Error bars: mean \pm SEM. $p \leq 0.05$. Post hoc unpaired two-sample $t$ tests with Bonferroni correction $(\boldsymbol{B}-\boldsymbol{D}, \boldsymbol{F})$ or unpaired two-sample $t$ tests $(\boldsymbol{A}, \boldsymbol{E}, \boldsymbol{G}$, $\boldsymbol{H}-\boldsymbol{J}):{ }^{*} p \leq 0.05 .{ }^{* *} p \leq 0.005$. ${ }^{* *} p \leq 0.005$.

edly that neurons from R579W mice produced statistically fewer action potentials across a series of depolarizing current steps (Fig. 9F; two-way repeated-measures ANOVA; $n=14$ R579W and 13 control; genotype effect, $F_{(1,25)}=16.8, p=0.0004$; current effect, $F_{(7,125)}=338.8, p<0.0001$; genotype $\times$ current interaction, $F_{(7,125)}=5.12, p<0.0001$; firing rate at $+400 \mathrm{pA}$, post hoc unpaired $t$ test with Bonferroni correction, $t_{(200)}=1.682, p=$ $0.016)$. Given the reduced firing rates and the statistically equivalent membrane resistances at $-70 \mathrm{mV}$ (Fig. 9B), we predicted that the threshold for firing an action potential would be more hyperpolarized in neurons from R579W mice. Indeed, action potentials in CA1 pyramidal neurons from R579W mice were initiated at a more depolarized membrane potential relative to controls (Fig. 9G; unpaired two-sample $t$ test; $n=14$ R579W and 13 control; $\left.t_{(25)}=4.203, p=0.0003\right)$. These neurons were also distinct in other firing properties, having a slower rate of action potential rise (Fig. $9 H$; unpaired two-sample $t$ test; $n=14 \mathrm{R} 579 \mathrm{~W}$ and 13 control; $\left.t_{(25)}=2.289, p=0.0308\right)$ and diminished action potential amplitude (Fig. 9I; unpaired two-sample $t$ test with Welch's correction; $n=14$ R579W and 13 control; $t_{(20.73)}=$ 3.461, $p=0.0024$ ), but were similar in half-width (Fig. 9J; unpaired two-sample $t$ test; $n=14 \mathrm{R} 579 \mathrm{~W}$ and 13 control; $t_{(25)}=$ $1.874, p=0.0727$ ).

When we examined the cHet mutant mice for similar alterations in firing properties, we found no reduction in intrinsic excitability between cHet and controls (Fig. 10A; two-way repeated-measures ANOVA; $n=10 \mathrm{cHet}$ and $11 \mathrm{control}$; genotype effect, $F_{(1,19)}=4.077, p=0.0578$; current effect, $F_{(7,133)}=$ $229.8, p<0.0001$; genotype $\times$ current interaction, $F_{(7,133)}=$ 2.188, $p=0.0392$ ) and no differences in firing threshold (Fig.
$10 B$; unpaired two-sample $t$ test; $n=10 \mathrm{cHet}$ and 11 control; $\left.t_{(19)}=0.4806, p=0.6363\right)$. We also observed that there were no differences in the rate of action potential rise (Fig. 10C; unpaired two-sample $t$ test; $n=10 \mathrm{cHet}$ and 11 control; $t_{(19)}=1.424, p=$ 0.1707 ), action potential amplitude (Fig. 10D; unpaired twosample $t$ test; $n=10 \mathrm{cHet}$ and 11 control; $t_{(19)}=0.9052, p=$ 0.3767 ), and half-width (Fig. 10E; unpaired two-sample $t$ test; $n=10 \mathrm{cHet}$ and 11 control; $\left.t_{(19)}=0.6051, p=0.5523\right)$. At the same time, we observed differences in input resistance (unpaired two-sample $t$ test; cHet, $n=10,89.76 \mathrm{M} \Omega \pm 2.9 \mathrm{M} \Omega$, control, $\left.n=10,105.6 \mathrm{M} \Omega \pm 3.8 \mathrm{M} \Omega ; t_{(18)}=3.478, p=0.0025\right)$ and membrane time constant (two-way repeated-measures ANOVA; $n=10 \mathrm{cHet}$ and 10 control; genotype effect, $F_{(1,18)}=5.432, p=$ 0.0316; injected current effect, $F_{(1,18)}=0.01903, p=0.8918$; genotype $\times$ injected current interaction, $F_{(1,18)}=0.1214, p=$ 0.7316; post hoc unpaired $t$ tests with Bonferroni corrections; $-400 \mathrm{pA}$, cHet $25.42 \pm 1.0 \mathrm{~ms}$ vs control $31.17 \pm 2.4 \mathrm{~ms}, t_{(36)}=$ 2.219, $p=0.0658 ;+400 \mathrm{pA}$, cHet $25.31 \pm 1.21 \mathrm{~ms}$ vs control $\left.31.41 \pm 2.3 \mathrm{~ms}, t_{(36)}=2.354, p=0.0483\right)$. Resting membrane potential was similar in cHet and control mice (unpaired twosample $t$ test; $n=10 \mathrm{cHet}$ and 11 control; cHet, $-69.8 \pm 1.6 \mathrm{mV}$, control, $\left.-67.2 \pm 1.2 \mathrm{mV} ; t_{(19)}=1.284, p=0.2146\right)$.

These results suggest that the precise genetic alteration of Tcf4 might dictate the consequences on intrinsic excitability and, moreover, that changes in excitability are unlikely to underlie the consistent LTP phenotype observed in all four PTHS mouse models. Therefore, we investigated whether changes in NMDARmediated signaling might provide a common deficit to account for the observed LTP enhancement. To test this, we first used field potential recordings to determine whether the enhanced LTP was 
A

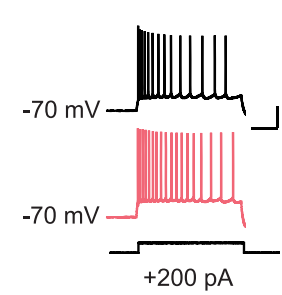

C

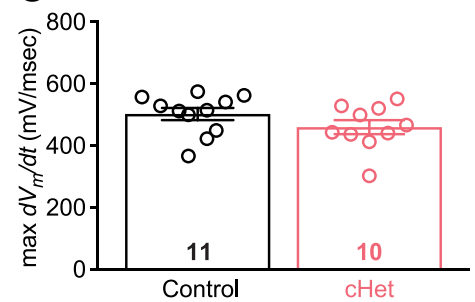

B

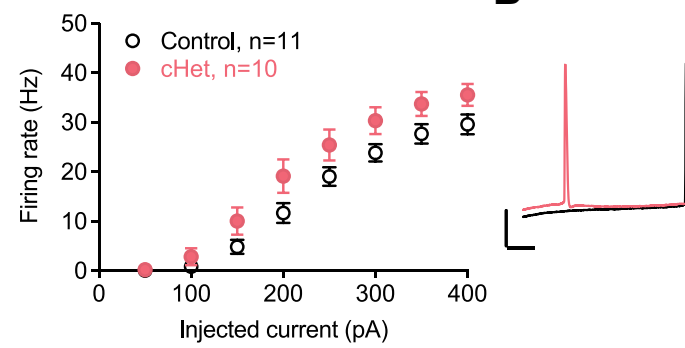

D

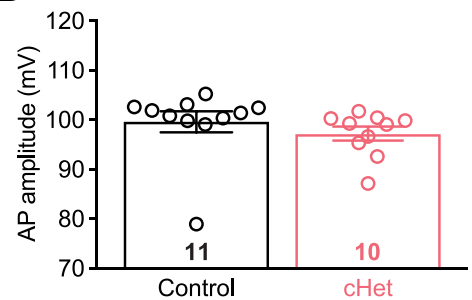

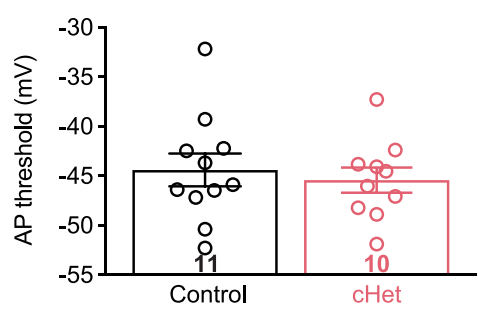

E

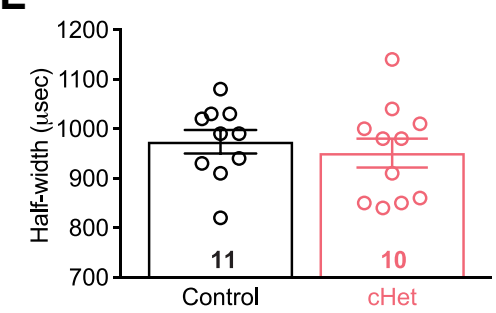

Figure 10. Active membrane properties in CA1 pyramidal neurons are largely unaffected by heterozygous deletion of Tff4. Shown are current-clamp measurements from CA1 pyramidal cells from chet mice and control littermates of intrinsic excitability and action potential features. A, Action potential firing rate to a depolarizing $(200 \mathrm{pA})$ current step. Sample trace scale bar, $250 \mathrm{~ms} \times 25 \mathrm{mV}$. $\boldsymbol{B}$, Firing threshold. Left, Example action potentials. Scale bar, $20 \mathrm{~ms} \times 25 \mathrm{mV}$. Right, Membrane voltage at which action potentials (APs) are initiated. $\mathbf{C}-\boldsymbol{E}$, Maximum AP $d V_{\mathrm{m}} / d t(\boldsymbol{C})$, height (D), and half-width $(\boldsymbol{E})$. Error bars indicate mean \pm SEM.

NMDAR dependent in R579W mice; the NMDAR antagonist $D, L$-APV blocked all LTP in R579W mice (Fig. 11A; unpaired two-sample $t$ test; $n=6 \mathrm{R} 579 \mathrm{~W}+\mathrm{APV}$ and 6 control + APV; $t_{(10)}=0.3654, p=0.7224$ ), demonstrating that the R579W mice did not gain an NMDAR-independent form of LTP in CA1. Subsequently, we conducted whole-cell voltage-clamp recordings to assess NMDAR function in CA1 pyramidal neurons and found that the NMDA/AMPA current ratio was enhanced in R579W mice compared with control littermates (Fig. 11B; unpaired twosample $t$ test; $n=28$ R579W and 31 control; $t_{(57)}=2.146, p=$ $0.0361)$. Likewise, we found that the NMDA/AMPA current ratio was enhanced in cHet mice compared with control littermates (Fig. 11F; unpaired two-sample $t$ test; $n=18 \mathrm{cHet}$ and 21 control; $\left.t_{(37)}=2.655, p=0.0116\right)$. Because AMPAR-mediated synaptic transmission appeared intact (Fig. 7), this finding suggests that NMDAR-mediated currents are selectively enhanced in R579W and $\mathrm{cHet}$ mice.

In addition, we measured the decay kinetics of the NMDARmediated component of the EPSCs and found a significant increase in the decay time in R579W mice compared with control littermates (Fig. 11C; unpaired two-sample $t$ test; $n=27$ R579W and 30 control; $\left.t_{(55)}=2.618, p=0.0114\right)$ and in cHet mice compared with control littermates (Fig. 11G; unpaired twosample $t$ test; $n=18 \mathrm{cHet}$ and 21 control; $t_{(37)}=2.077 ; p=$ $0.0448)$. This finding was confirmed in R579W mice by measurements of the decay kinetics of pharmacologically isolated NMDAR-mediated currents (Fig. $11 D ; n=14$ R579W and 12 control; unpaired two-sample $t$ test, $\left.t_{(23)}=2.317, p=0.0298\right)$. Because prolonged NMDAR-mediated currents may result from alterations in NMDAR subunit composition (Carmignoto and Vicini, 1992; Flint et al., 1997; Paoletti et al., 2013), we measured the sensitivity of NMDAR-mediated currents in CA1 pyramidal cells to the NR2B-selective antagonist ifenprodil (de Marchena et al., 2008). After a $20 \mathrm{~min}$ period of ifenprodil wash-on in the presence of DNQX, the amplitude of NMDAR-mediated currents were suppressed in neurons from both R579W mutants and control littermates; however, the reduction was significantly enhanced in the mutants (Fig. 11E; unpaired two-sample $t$ test; $n=$
7 mutant and 10 control; $\left.t_{(15)}=2.563, p=0.0216\right)$. This suggests that CA1 neurons in $\mathrm{R} 579 \mathrm{~W}$ mice have a relative increase in synaptic NR2B-containing NMDARs. Collectively, our findings suggest that NMDAR function is enhanced in R579W and cHet mice and potentially all PTHS mouse models.

\section{Discussion}

We used an intersectional approach to reveal common pathophysiological deficits arising from distinct classes of PTHS-linked $T c f 4$ mutations. We compared preexisting mouse models of Tcf4 disruption (cHet and CNS-cHet mice) (Bergqvist et al., 2000) with novel point mutation and indel mouse models (R579W and $\Delta 574-579$ mice) and found that these models consistently present with certain phenotypes observed in PTHS individuals (Amiel et al., 2007; Zweier et al., 2007; de Pontual et al., 2009). Furthermore, these Tcf4 mutations had convergent impacts on behavior: both cHet and R579W mice exhibited hyperactivity, decreased anxiety, and deficient spatial learning and memory. The reported deficits, many of which could arise from altered hippocampal function (Bast and Feldon, 2003; Bannerman et al., 2004; Leussis and Bolivar, 2006), were accompanied by enhanced hippocampal LTP in every mouse model tested. The enhanced LTP was linked to NMDAR hyperfunction in R579W mice and cHet mice, the only mouse models we studied in this aspect, providing one mechanistic basis for deficits observed in PTHS and a potential therapeutic opportunity. Moreover, our data identify a number of consistent behavioral and electrophysiological phenotypes across PTHS model mice, which provide a robust platform for preclinical studies aiming to treat PTHS.

Identifying penetrant consequences of TCF4 disruption is critical for guiding future PTHS therapeutics, a goal that is particularly important given the challenges in identifying consistent phenotypes across mutations of a single gene for other neurodevelopmental disorders. This issue is perhaps best exemplified by the high-confidence autism risk gene SHANK3, in which the type of mutation and the exon affected dramatically affect the severity of intellectual disability, the precise nature of autism- and schizophrenia-like symptoms, and other clinical features (Jiang and 


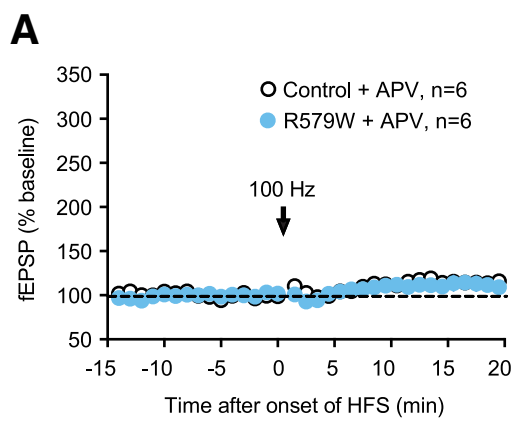

B

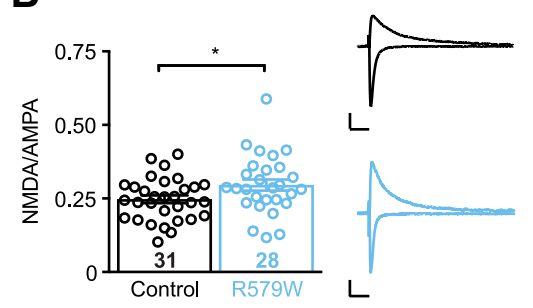

C

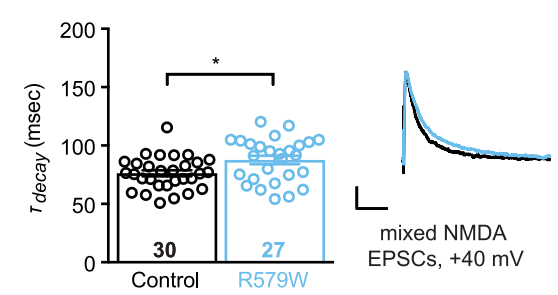

D

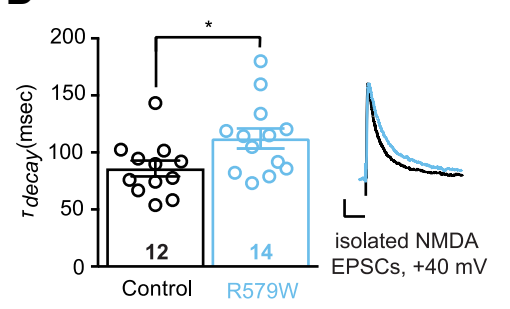

E

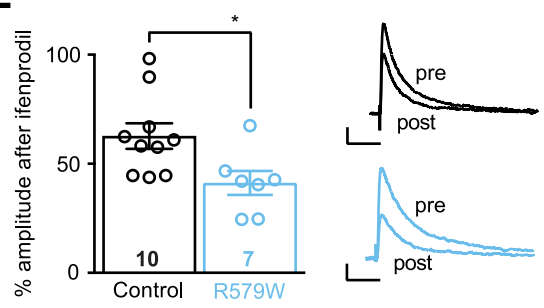

G

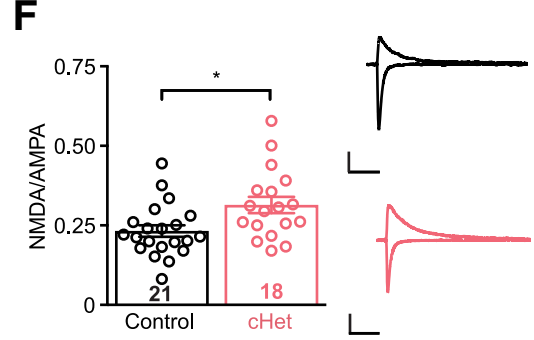

(Stefansson et al., 2009; Navarrete et al., 2013; Quednow et al., 2014). Furthermore, it is unclear to what degree PTHSrelated phenotypes vary with genotype in patients due to sparse clinical data, although previous studies suggest that there are both highly penetrant and variable phenotypes (Giurgea et al., 2008; Rosenfeld et al., 2009; Whalen et al., 2012). Different PTHS mouse models had the potential to vary in behavioral and synaptic phenotypes, yet we found largely homogenous phenotypes among the mice harboring point mutations or small deletions compromising the function of the critical bHLH domain. The observed overlapping phenotypes across PTHS mouse models provide insights for identifying potential drug targets and outcome measures for assessing preclinical therapeutic efficacy.

Our finding of reduced adult brain weight and body weight in our mouse models is consistent with the features of microcephaly and hypotonia in PTHS. Qualitatively, the reductions in brain size appear to be uniform, consistent with the observation that TCF4 is expressed in nearly every brain area (Sepp et al., 2011). Interestingly, previous work in adult Tcf4 ${ }^{+/-}$mice (Rannals et al., 2016a, b) showed no apparent changes in body weight (Grubišić et al., 2015); brain weight was not assessed. This discrepancy may be due to mouse strain differences: the $T c f 4^{+/-}$mice were on a mixed C57BL/6-129SF1/J background, whereas our mouse models were on a congenic C57BL/6 background. Our behavioral characterization of cHet and $\mathrm{R} 579 \mathrm{~W}$ mice showed that these mice expressed hyperactivity in the open field and decreased anxiety in the elevated plus maze, but also lacked sociability deficits and reliable long-lasting impairment to auditory startle. In addition, both $\mathrm{R} 579 \mathrm{~W}$ and $\mathrm{cHet}$ mice displayed learning and memory deficits in the Morris water maze; however, subtle genotypic differences were apparent in their performance in this hippocampus-dependent task that might merit further investigation using additional spatial memory tasks. Consistent

Ehlers, 2013). This diversity has complicated the preclinical study of SHANK3-related disorders such as Phelan-McDermid syndrome (Wilson et al., 2003) because Shank3 mouse models have yielded inconsistent neurobehavioral, synaptic, and molecular phenotypes (Jiang and Ehlers, 2013). However, the issue may be clarified by a recent study of the shared and distinct features of autism- or schizophrenia-causing point mutations on exon 21 (Zhou et al., 2016), highlighting the need to produce accurate disease models. Likewise, PTHS-relevant mutations of TCF4 span a wide spectrum (Sepp et al., 2012; Whalen et al., 2012) and TCF4 has been linked to both autism (Stessman et al., 2017) and schizophrenia with our data, $T c f 4^{+/-}$mice are also hyperactive in the open field and demonstrate learning and memory deficits in the Morris water maze, as well as other hippocampus-dependent tasks (Kennedy et al., 2016). Likewise, both cHet and Tcf4 ${ }^{+/-}$mice (but not R579W mice) demonstrate deficits in habituation to novel environments at least $30 \mathrm{~min}$ after entering the open field (Kennedy et al., 2016). Our findings across PTHS mouse models, combined with data from other investigators in the $T c f 4^{+/-}$mice (Kennedy et al., 2016), emphasize the penetrance of the open-field and hippocampus-dependent cognition deficits as central features of PTHS mouse models. However, $T c f 4^{+/-}$mice also have behaviors that 
were inconsistent with our findings: the $T c f 4^{+/-}$mice are not only anxious in the elevated plus maze, but also asocial and hyperresponsive to auditory stimuli (Kennedy et al., 2016). The disparities between these findings, particularly between $T c f 4^{+1-}$ and cHet mice, which both model a similar disruption of Tcf4, may be due to potential but untested differences in these tasks because they commonly appear between backgrounds and among substrains of the similar backgrounds (Balogh et al., 1999; Moy et al., 2007; Bryant et al., 2008; Matsuo et al., 2010). Alternatively, there may be variations in how each task was performed between studies. Such variations should be investigated closely in further work, possibly as a basis for examining variability in molecular targets downstream of TCF4 in PTHS. Despite subtle differences across PTHS mouse models, our data demonstrate that that there is a large core set of behavioral deficits around which preclinical studies can be designed.

Enhanced hippocampal LTP was a particularly penetrant feature across our four PTHS mouse models, which, together with a similar finding in $T c f 4^{+/-}$mice (Kennedy et al., 2016), comprises the most consistent phenotype in the PTHS literature to date. Consistent with the concept that neurodevelopmental disorders may largely be a disease of the synapse (Zoghbi and Bear, 2012), we found a strong synaptic phenotype, enhanced NMDARmediated LTP, that may underlie cognitive dysfunction observed in Tcf4 mouse models (Brzózka et al., 2010; Kennedy et al., 2016) and in individuals with PTHS (Amiel et al., 2007; Brockschmidt et al., 2007; Zweier et al., 2007; Rosenfeld et al., 2009). There is a complex relationship between LTP and cognitive performance (Lee and Silva, 2009), as evidenced by studies showing enhanced LTP impairs learning in mouse models with genetic alterations in IRSp53 (Kim et al., 2009), LIMK1 (Meng et al., 2002), PSD-95 (Migaud et al., 1998), syndecan-3 (Kaksonen et al., 2002), dystrophin (Vaillend et al., 2004), or PTP $\delta$ (Uetani et al., 2000), or in rodents exposed prenatally to valproic acid (Rinaldi et al., 2007; Roullet et al., 2013). Therefore, our finding suggests that PTHSrelated Tcf4 disruption broadly perturbs the mechanisms underlying LTP induction, negatively affecting learning and memory. Upon closer investigation of the electrophysiology of CA1 pyramidal cells in R579W mice, we found reduced intrinsic excitability in the R579W mice, but not the cHet mice, indicating a potentially divergent phenotype among the models. The excitability defect in the R579W mice, also recently linked to Tcf4 perturbation in prefrontal layer $2 / 3$ pyramidal neurons (Rannals et al., 2016a, b), is surprising in light of the observed LTP enhancement. However, this defect may be overcome by enhanced NMDAR function, which was suggested by the increased NMDA/AMPA current ratio and intact AMPAR-mediated synaptic transmission. Likewise, this NMDAR hyperfunction appears sufficient to enhance LTP in the cHet mice. This shared alteration may be due to NMDAR subunit dysfunction, as suggested by the prolonged NMDAR-mediated current decay time and increased ifenprodil sensitivity, which may favor Grin $2 b$ function over Grin2a function, as well as the observed changes in Grin2a expression in $\mathrm{Tcf}^{+/-}$mice (Kennedy et al., 2016). Together, these results pinpoint a key mechanistic insight that may apply broadly across PTHS-relevant Tcf4 mutations.

Our finding of hippocampal NMDAR hyperfunction in R579W mice, coupled with findings of prefrontal cortex NMDAR hyperfunction in $T c f 4^{+\prime-}$ mice (Page et al., 2017), suggests that NMDAR antagonism may be a feasible therapeutic strategy for many PTHS individuals. NMDAR hyperfunction has been observed in many neurodevelopmental disorders (Chez et al., 2007; Rinaldi et al., 2007; Kim et al., 2009; Etherton et al., 2011), raising the possibil- ity that drugs correcting NMDAR function may rescue core disease features (Lee et al., 2015; Katz et al., 2016a, b). For example, a recent study of Rett syndrome, which has a clinical presentation similar to PTHS (Brockschmidt et al., 2007; Zweier et al., 2007, 2008; Giurgea et al., 2008; Tan et al., 2014), showed that chronic administration of a subsaturating dose of the noncompetitive NMDAR antagonist ketamine was sufficient to extend lifespan and correct anatomical and physiological abnormalities (Patrizi et al., 2016). These results have led to the idea that NMDAR antagonists such as ketamine might offer a treatment for some features of Rett syndrome (Kron et al., 2012; Katz et al., 2016b). In PTHS, there has been informal clinical interest in the effectiveness of the NMDAR antagonist amantadine (Pitt-Hopkins Research Foundation, personal communications). Our data support an assessment of the efficacy of amantadine or the pharmacologically similar NMDAR antagonist memantine (Kos and Popik, 2005; Rammes et al., 2008) in treating the core features of PTHS in model mice. Our study further outlines penetrant and reproducible core features of PTHS mouse models, including enhanced hippocampal LTP, hyperactivity, and deficient hippocampus-dependent learning and memory, representing potential biomarkers of the preclinical effectiveness of therapeutic approaches, including NMDAR antagonism.

\section{References}

Amiel J, Rio M, de Pontual L, Redon R, Malan V, Boddaert N, Plouin P, Carter NP, Lyonnet S, Munnich A, Colleaux L (2007) Mutations in TCF4, encoding a class I basic helix-loop-helix transcription factor, are responsible for Pitt-Hopkins syndrome, a severe epileptic encephalopathy associated with autonomic dysfunction. Am J Hum Genet 80:988-993. CrossRef Medline

Balogh SA, McDowell CS, Stavnezer AJ, Denenberg VH (1999) A behavioral and neuroanatomical assessment of an inbred substrain of 129 mice with behavioral comparisons to C57BL/6J mice. Brain Res 836:38-48. CrossRef Medline

Bannerman DM, Rawlins JN, McHugh SB, Deacon RM, Yee BK, Bast T, Zhang WN, Pothuizen HH, Feldon J (2004) Regional dissociations within the hippocampus-memory and anxiety. Neurosci Biobehav Rev 28:273-283. CrossRef Medline

Bast T, Feldon J (2003) Hippocampal modulation of sensorimotor processes. Prog Neurobiol 70:319-345. CrossRef Medline

Bergqvist I, Eriksson M, Saarikettu J, Eriksson B, Corneliussen B, Grundström T, Holmberg D (2000) The basic helix-loop-helix transcription factor E2-2 is involved in T lymphocyte development. Eur J Immunol 30:2857-2863. CrossRef Medline

Berrios J, Stamatakis AM, Kantak PA, McElligott ZA, Judson MC, Aita M, Rougie M, Stuber GD, Philpot BD (2016) Loss of UBE3A from THexpressing neurons suppresses GABA co-release and enhances VTA-NAc optical self-stimulation. Nat Commun 7:10702. CrossRef Medline

Bischofberger J, Engel D, Li L, Geiger JR, Jonas P (2006) Patch-clamp recording from mossy fiber terminals in hippocampal slices. Nat Protoc 1:2075-2081. CrossRef Medline

Blake DJ, Forrest M, Chapman RM, Tinsley CL, O’Donovan MC, Owen MJ (2010) TCF4, schizophrenia, and Pitt-Hopkins syndrome. Schizophr Bull 36:443-447. CrossRef Medline

Brockschmidt A, Todt U, Ryu S, Hoischen A, Landwehr C, Birnbaum S, Frenck W, Radlwimmer B, Lichter P, Engels H, Driever W, Kubisch C, Weber RG (2007) Severe mental retardation with breathing abnormalities (Pitt-Hopkins syndrome) is caused by haploinsufficiency of the neuronal bHLH transcription factor TCF4. Hum Mol Genet 16:1488-1494. CrossRef Medline

Bryant CD, Zhang NN, Sokoloff G, Fanselow MS, Ennes HS, Palmer AA, McRoberts JA (2008) Behavioral differences among C57BL/6 substrains: implications for transgenic and knockout studies. J Neurogenet 22:315-331. CrossRef Medline

Brzózka MM, Radyushkin K, Wichert SP, Ehrenreich H, Rossner MJ (2010) Cognitive and sensorimotor gating impairments in transgenic mice overexpressing the schizophrenia susceptibility gene Tcf4 in the brain. Biol Psychiatry 68:33-40. CrossRef Medline 
Carmignoto G, Vicini S (1992) Activity-dependent decrease in NMDA receptor responses during development of the visual cortex. Science 258: 1007-1011. CrossRef Medline

Chez MG, Burton Q, Dowling T, Chang M, Khanna P, Kramer C (2007) Memantine as adjunctive therapy in children diagnosed with autistic spectrum disorders: an observation of initial clinical response and maintenance tolerability. J Child Neurol 22:574-579. CrossRef Medline

de Pontual L, et al. (2009) Mutational, functional, and expression studies of the TCF4 gene in Pitt-Hopkins syndrome. Hum Mut 30:669-676. CrossRef Medline

de Marchena J, Roberts AC, Middlebrooks PG, Valakh V, Yashiro K, Wilfley LR, Philpot BD (2008) NMDA receptor antagonists reveal age-dependent differences in the properties of visual cortical plasticity. J Neurophysiol 100: 1936-1948. CrossRef Medline

Dembrow NC, Chitwood RA, Johnston D (2010) Projection-specific neuromodulation of medial prefrontal cortex neurons. J Neurosci 30:1692216937. CrossRef Medline

de Winter CF, Baas M, Bijlsma EK, van Heukelingen J, Routledge S, Hennekam RC (2016) Phenotype and natural history in 101 individuals with Pitt-Hopkins syndrome through an internet questionnaire system. Orphanet J Rare Dis 11:37. CrossRef Medline

Etherton M, Földy C, Sharma M, Tabuchi K, Liu X, Shamloo M, Malenka RC, Südhof TC (2011) Autism-linked neuroligin-3 R451C mutation differentially alters hippocampal and cortical synaptic function. Proc Natl Acad Sci U S A 108:13764-13769. CrossRef Medline

Flint AC, Maisch US, Weishaupt JH, Kriegstein AR, Monyer H (1997) NR2A subunit expression shortens NMDA receptor synaptic currents in developing neocortex. J Neurosci 17:2469-2476. Medline

Giurgea I, Missirian C, Cacciagli P, Whalen S, Fredriksen T, Gaillon T, Rankin J, Mathieu-Dramard M, Morin G, Martin-Coignard D, Dubourg C, Chabrol B, Arfi J, Giuliano F, Claude Lambert J, Philip N, Sarda P, Villard L, Goossens M, Moncla A (2008) TCF4 deletions in Pitt-Hopkins Syndrome. Hum Mut 29:E242-E251. CrossRef Medline

Grubišić V, Kennedy AJ, Sweatt JD, Parpura V (2015) Pitt-Hopkins mouse model has altered particular gastrointestinal transits in vivo. Autism Res 8:629-633. CrossRef Medline

Hasi M, Soileau B, Sebold C, Hill A, Hale DE, O’Donnell L, Cody JD (2011) The role of the TCF4 gene in the phenotype of individuals with $18 \mathrm{q}$ segmental deletions. Hum Genet 130:777-787. CrossRef Medline

Hsu PD, Lander ES, Zhang F (2014) Development and applications of CRISPR-Cas9 for genome engineering. Cell 157:1262-1278. CrossRef Medline

Jiang YH, Ehlers MD (2013) Modeling autism by SHANK gene mutations in mice. Neuron 78:8-27. CrossRef Medline

Kaksonen M, Pavlov I, Võikar V, Lauri SE, Hienola A, Riekki R, Lakso M, Taira T, Rauvala H (2002) Syndecan-3-deficient mice exhibit enhanced LTP and impaired hippocampus-dependent memory. Mol Cell Neurosci 21:158-172. CrossRef Medline

Katz DM, Menniti FS, Mather RJ (2016a) N-methyl-D-aspartate receptors, ketamine, and Rett syndrome: something special on the road to treatments? Biol Psychiatry 79:710-712. CrossRef Medline

Katz DM, Bird A, Coenraads M, Gray SJ, Menon DU, Philpot BD, Tarquinio DC (2016b) Rett syndrome: crossing the threshold to clinical translation. Trends Neurosci 39:100-113. CrossRef Medline

Kennedy AJ, Rahn EJ, Paulukaitis BS, Savell KE, Kordasiewicz HB, Wang J, Lewis JW, Posey J, Strange SK, Guzman-Karlsson MC, Phillips SE, Decker K, Motley ST, Swayze EE, Ecker DJ, Michael TP, Day JJ, Sweatt JD (2016) Tcf4 regulates synaptic plasticity, DNA methylation, and memory function. Cell Rep 16:2666-2685. CrossRef Medline

Kim MH, Choi J, Yang J, Chung W, Kim JH, Paik SK, Kim K, Han S, Won H, Bae YS, Cho SH, Seo J, Bae YC, Choi SY, Kim E (2009) Enhanced NMDA receptor-mediated synaptic transmission, enhanced long-term potentiation, and impaired learning and memory in mice lacking IRSp53. J Neurosci 29:1586-1595. CrossRef Medline

Kos T, Popik P (2005) A comparison of the predictive therapeutic and undesired side-effects of the NMDA receptor antagonist, memantine, in mice. Behav Pharmacol 16:155-161. CrossRef Medline

Kron M, Howell CJ, Adams IT, Ransbottom M, Christian D, Ogier M, Katz DM (2012) Brain activity mapping in Mecp2 mutant mice reveals functional deficits in forebrain circuits, including key nodes in the default mode network, that are reversed with ketamine treatment. J Neurosci $32: 13860-13872$.
Lee EJ, Choi SY, Kim E (2015) NMDA receptor dysfunction in autism spectrum disorders. Curr Opin Pharmacol 20:8-13. CrossRef Medline

Lee YS, Silva AJ (2009) The molecular and cellular biology of enhanced cognition. Nat Rev Neurosci 10:126-140. CrossRef Medline

Leussis MP, Bolivar VJ (2006) Habituation in rodents: a review of behavior, neurobiology, and genetics. Neurosci Biobehav Rev 30:1045-1064. CrossRef Medline

Marangi G, Zollino M (2015) Pitt-Hopkins syndrome and differential diagnosis: a molecular and clinical challenge. J Pediatr Genet 4:168-176. CrossRef Medline

Matsuo N, Takao K, Nakanishi K, Yamasaki N, Tanda K, Miyakawa T (2010) Behavioral profiles of three C57BL/6 substrains. Front Behav Neurosci 4:29. CrossRef Medline

Meng Y, Zhang Y, Tregoubov V, Janus C, Cruz L, Jackson M, Lu WY, MacDonald JF, Wang JY, Falls DL, Jia Z (2002) Abnormal spine morphology and enhanced LTP in LIMK-1 knockout mice. Neuron 35:121-133. CrossRef Medline

Migaud M, Charlesworth P, Dempster M, Webster LC, Watabe AM, Makhinson M, He Y, Ramsay MF, Morris RG, Morrison JH, O’Dell TJ, Grant SG (1998) Enhanced long-term potentiation and impaired learning in mice with mutant postsynaptic density-95 protein. Nature 396:433-439. CrossRef Medline

Moy SS, Nadler JJ, Young NB, Perez A, Holloway LP, Barbaro RP, Barbaro JR, Wilson LM, Threadgill DW, Lauder JM, Magnuson TR, Crawley JN (2007) Mouse behavioral tasks relevant to autism: phenotypes of 10 inbred strains. Behav Brain Res 176:4-20. CrossRef Medline

Navarrete K, Pedroso I, De Jong S, Stefansson H, Steinberg S, Stefansson K, Ophoff RA, Schalkwyk LC, Collier DA (2013) TCF4 (e2-2; ITF2): a schizophrenia-associated gene with pleiotropic effects on human disease. Am J Med Genet B Neuropsychiatr Genet 162B:1-16. CrossRef Medline

Page SC, Hamersky GR, Gallo RA, Rannals MD, Calcaterra NE, Campbell MN, Mayfield B, Briley A, Phan BN, Jaffe AE, Maher BJ (2017) The schizophrenia- and autism-associated gene, transcription factor 4 regulates the columnar distribution of layer $2 / 3$ prefrontal pyramidal neurons in an activity-dependent manner. Mol Psychiatry. Advance online publication. Retrieved on Mar 14, 2017. CrossRef

Paoletti P, Bellone C, Zhou Q (2013) NMDA receptor subunit diversity: impact on receptor properties, synaptic plasticity and disease. Nat Rev Neurosci 14:383-400. CrossRef Medline

Patrizi A, Picard N, Simon AJ, Gunner G, Centofante E, Andrews NA, Fagiolini M (2016) Chronic administration of the N-methyl-D-aspartate receptor antagonist ketamine improves Rett syndrome phenotype. Biol Psychiatry 79:755-764. CrossRef Medline

Philpot BD, Weisberg MP, Ramos MS, Sawtell NB, Tang YP, Tsien JZ, Bear MF (2001) Effect of transgenic overexpression of NR2B on NMDA receptor function and synaptic plasticity in visual cortex. Neuropharmacology 41:762-770. CrossRef Medline

Quednow BB, Brzózka MM, Rossner MJ (2014) Transcription factor 4 (TCF4) and schizophrenia: integrating the animal and the human perspective. Cell Mol Life Sci 71:2815-2835. CrossRef Medline

Rammes G, Danysz W, Parsons CG (2008) Pharmacodynamics of memantine: an update. Curr Neuropharmacol 6:55-78. CrossRef Medline

Rannals MD, Page SC, Campbell MN, Gallo RA, Mayfield B, Maher BJ (2016a) Neurodevelopmental models of transcription factor 4 deficiency converge on a common ion channel as a potential therapeutic target for Pitt Hopkins syndrome. Rare Dis 4:e1220468. CrossRef Medline

Rannals MD, Hamersky GR, Page SC, Campbell MN, Briley A, Gallo RA, Phan BN, Hyde TM, Kleinman JE, Shin JH, Jaffe AE, Weinberger DR, Maher BJ (2016b) Psychiatric risk gene transcription factor 4 regulates intrinsic excitability of prefrontal neurons via repression of SCN10a and KCNQ1. Neuron 90:43-55. CrossRef Medline

Rinaldi T, Kulangara K, Antoniello K, Markram H (2007) Elevated NMDA receptor levels and enhanced postsynaptic long-term potentiation induced by prenatal exposure to valproic acid. Proc Natl Acad Sci U S A 104:13501-13506. CrossRef Medline

Rosenfeld JA, Leppig K, Ballif BC, Thiese H, Erdie-Lalena C, Bawle E, Sastry S, Spence JE, Bandholz A, Surti U, Zonana J, Keller K, Meschino W, Bejjani BA, Torchia BS, Shaffer LG (2009) Genotype-phenotype analysis of TCF4 mutations causing Pitt-Hopkins syndrome shows increased seizure activity with missense mutations. Genet Med 11:797-805. CrossRef Medline

Roullet FI, Lai JK, Foster JA (2013) In utero exposure to valproic acid and 
autism-a current review of clinical and animal studies. Neurotoxicol Teratol 36:47-56. CrossRef Medline

Routh BN, Johnston D, Harris K, Chitwood RA (2009) Anatomical and electrophysiological comparison of CA1 pyramidal neurons of the rat and mouse. J Neurophysiol 102:2288-2302. CrossRef Medline

Sepp M, Kannike K, Eesmaa A, Urb M, Timmusk T (2011) Functional diversity of human basic helix-loop-helix transcription factor TCF4 isoforms generated by alternative $5^{\prime}$ exon usage and splicing. PLoS One 6:e22138. CrossRef Medline

Sepp M, Pruunsild P, Timmusk T (2012) Pitt-Hopkins syndrome-associated mutations in TCF4 lead to variable impairment of the transcription factor function ranging from hypomorphic to dominant-negative effects. Hum Mol Genet 21:2873-2888. CrossRef Medline

Stefansson H, et al. (2009) Common variants conferring risk of schizophrenia. Nature 460:744-747. Medline

Stessman HA, et al. (2017) Targeted sequencing identifies 91 neurodevelopmental-disorder risk genes with autism and developmental-disability biases. Nat Genet 49:515-526. CrossRef Medline

Tamberg L, Sepp M, Timmusk T, Palgi M (2015) Introducing Pitt-Hopkins syndrome-associated mutations of TCF4 to Drosophila daughterless. Biol Open 4:1762-1771. CrossRef Medline

Tan WH, Bird LM, Thibert RL, Williams CA (2014) If not Angelman, what is it? A review of Angelman-like syndromes. Am J Med Genet A 164A: 975-992. Medline

Uetani N, Kato K, Ogura H, Mizuno K, Kawano K, Mikoshiba K, Yakura H, Asano M, Iwakura Y (2000) Impaired learning with enhanced hippocampal long-term potentiation in PTPdelta-deficient mice. EMBO J 19:2775-2785. CrossRef Medline

Vaillend C, Billard JM, Laroche S (2004) Impaired long-term spatial and recognition memory and enhanced CA1 hippocampal LTP in the dystrophin-deficient Dmd(mdx) mouse. Neurobiol Dis 17:10-20. CrossRef Medline
Wallace ML, Burette AC, Weinberg RJ, Philpot BD (2012) Maternal loss of Ube3a produces an excitatory/inhibitory imbalance through neuron type-specific synaptic defects. Neuron 74:793-800. CrossRef Medline

Whalen S, et al. (2012) Novel comprehensive diagnostic strategy in PittHopkins syndrome: clinical score and further delineation of the TCF4 mutational spectrum. Hum Mut 33:64-72. CrossRef Medline

Wilson HL, Wong AC, Shaw SR, Tse WY, Stapleton GA, Phelan MC, Hu S, Marshall J, McDermid HE (2003) Molecular characterisation of the $22 \mathrm{q} 13$ deletion syndrome supports the role of haploinsufficiency of SHANK3/PROSAP2 in the major neurological symptoms. J Med Genet 40:575-584. CrossRef Medline

Zhou Y, Kaiser T, Monteiro P, Zhang X, Van der Goes MS, Wang D, Barak B, Zeng M, Li C, Lu C, Wells M, Amaya A, Nguyen S, Lewis M, Sanjana N, Zhou Y, Zhang M, Zhang F, Fu Z, Feng G (2016) Mice with Shank3 mutations associated with ASD and schizophrenia display both shared and distinct defects. Neuron 89:147-162. CrossRef Medline

Zhuang Y, Cheng P, Weintraub H (1996) B-lymphocyte development is regulated by the combined dosage of three basic helix-loop-helix genes, E2A, E2-2, and HEB. Mol Cell Biol 16:2898-2905. CrossRef Medline

Zoghbi HY, Bear MF (2012) Synaptic dysfunction in neurodevelopmental disorders associated with autism and intellectual disabilities. Cold Spring Harb Perspect Biol 4: pii: a009886. CrossRef Medline

Zweier C, et al. (2008) Further delineation of Pitt-Hopkins syndrome: phenotypic and genotypic description of 16 novel patients. J Med Genet 45:738-744. CrossRef Medline

Zweier C, Peippo MM, Hoyer J, Sousa S, Bottani A, Clayton-Smith J, Reardon W, Saraiva J, Cabral A, Gohring I, Devriendt K, de Ravel T, Bijlsma EK, Hennekam RC, Orrico A, Cohen M, Dreweke A, Reis A, Nurnberg P, Rauch A (2007) Haploinsufficiency of TCF4 causes syndromal mental retardation with intermittent hyperventilation (Pitt-Hopkins syndrome). Am J Hum Genet 80:994-1001. CrossRef Medline 